\title{
NaDNA-bipyridyl-(ethylenediamine)platinum (II) complex: Structure in oriented wet-spun films and fibers
}

\author{
S. A. Lee, ${ }^{1}$ H. Grimm, ${ }^{2}$ W. Pohle, ${ }^{3}$ W. Scheiding, ${ }^{3}$ L. van Dam, ${ }^{4}$ Z. Song,,${ }^{4}$ M. H. Levitt, ${ }^{4}$ N. Korolev, ${ }^{4}$ \\ A. Szabó, ${ }^{1}$ and A. Rupprecht ${ }^{4}$ \\ ${ }^{1}$ Department of Physics \& Astronomy, University of Toledo, Toledo, Ohio 43606 \\ ${ }^{2}$ Institüt für Festkörperforschung, Forschungszentrum, D-52425 Jülich, Germany \\ ${ }^{3}$ Institüt für Molekularbiologie, Friedrich-Schiller-Universität Jena, D-07708 Jena, Germany \\ ${ }^{4}$ Division of Physical Chemistry, Arrhenius Laboratory, University of Stockholm, S-106 91, Stockholm, Sweden
}

(Received 18 May 2000)

\begin{abstract}
Complexes of NaDNA with bipyridyl-(ethylenediamine)platinum(II) (abbreviated [(bipy)Pt(en) $]^{2+}$ ) in solid, oriented films, prepared with a wet-spinning method, have been studied using x-ray diffraction, elastic neutron scattering, two-dimensional magic-angle-spinning nuclear magnetic resonance (NMR), infrared (IR) linear dichroism, and IR absorption. All of these experiments indicate that the DNA in this complex is in the $B$ conformation. The neutron diffraction experiments reveal that the rise per residue is $3.31 \AA$, indicating that the $[\text { (bipy) } \mathrm{Pt}(\mathrm{en})]^{2+}$ molecular ion causes a small distortion of the $B$ conformation. The neutron data in the direction perpendicular to the helical axis are consistent with a centered orthorhombic unit cell with $a$ $=22.65 \AA$ and $b=32.2 \AA$. The NMR and IR experiments show that the orientation of phosphate groups in the DNA $[\text { (bipy)Pt(en) }]^{2+}$ complex is the same as that observed for pure DNA in the $B$ conformation. The IR experiments also show that the $[(\text { bipy }) \mathrm{Pt}(\mathrm{en})]^{2+}$ molecular ion stabilizes the $B$ conformation of DNA down to $59 \%$ relative humidity, a low water activity. Mechanochemical experiments on wet-spun NaDNA fibers in $68 \%$ ethanol with and without $[(\text { bipy }) \operatorname{Pt}(\text { en })]^{2+}$ reveal a $9 \%$ elongation of the DNA fibers as the complex is formed.
\end{abstract}

PACS number(s): 87.64.Bx, 87.64.Je, 87.64.Hd

\section{INTRODUCTION}

Understanding the interactions of DNA with its various ligands is of tremendous importance for developing theoretical models of biological processes such as replication and transcription and for the development of new anticancer drugs that bind to DNA. Therefore, numerous studies have been devoted to DNA-ligand complexes [1-4]. The complex of DNA with the molecular ion bipyridyl-(ethylenediamine)platinum(II) (abbreviated as $[(\text { bipy }) \mathrm{Pt}(\mathrm{en})]^{2+}$ and shown in Fig. 1) was first reported in 1976 by Lippard and co-workers [5,6]. Their x-ray diffraction data from oriented fibers gave evidence for a $10.2 \AA$ spacing along the helical direction. This observation led them to suggest that the $[(\text { bipy }) \operatorname{Pt}(\text { en })]^{2+}$ molecular ion intercalates the DNA via the nearest neighbor exclusion rule: one $[(\text { bipy }) \mathrm{Pt}(\mathrm{en})]^{2+}$ for every two base pairs. They also performed gel electrophoresis and sedimentation velocity experiments on closed-circular and nicked-circular DNA and found that the attachment of the $[(\text { bipy }) \mathrm{Pt}(\mathrm{en})]^{2+}$ changed the winding of the DNA double helix. Their data also showed that the $[(\text { bipy }) \mathrm{Pt}(\mathrm{en})]^{2+}$ compound changes the winding of DNA less than the ethidium ion does. Their sedimentation velocity studies verified the same result: $[\text { (bipy) } \mathrm{Pt}(\mathrm{en})]^{2+}$ changes the winding of DNA by an amount less than the ethidium ion. They also found that the $[(\text { bipy }) \mathrm{Pt}(\mathrm{en})]^{2+}$ compound interferes with the usual fluorescence enhancement of ethidium upon attachment to DNA. The $[(\text { bipy }) \mathrm{Pt}(\mathrm{en})]^{2+}$ molecular ion can interfere with the intercalation of the ethidium ion by occupying either the initial binding sites on the outside of the double helix or the intercalation sites themselves. Pelleting experiments indicate that the apparent binding constant of $[(\text { bipy }) \mathrm{Pt}(\mathrm{en})]^{2+}$ to DNA is more than an order of magnitude weaker than the apparent binding constant of the ethidium ion to DNA [7].

Arnott and co-workers performed further x-ray fiber diffraction studies of the DNA $\cdot[(\text { bipy }) \mathrm{Pt}(\mathrm{en})]^{2+}$ complex $[8,9]$ and also observed an $\mathrm{x}$-ray reflection corresponding to a $10.2 \AA$ spacing. They proposed on the basis of the $\mathrm{x}$-ray data that the DNA adopts a novel "ladder" conformation ( $L$-DNA) in this complex. The bases are still hydrogen bonded in the Watson-Crick manner. In each base pair, one base is in the syn orientation while its partner is anti. The syn base is attached to a $\mathrm{C}^{\prime}$ endo sugar and the anti base is attached to a $\mathrm{C}^{\prime}{ }^{\prime}$ endo sugar. In their model structure, the insertion of the intercalating [(bipy) $\mathrm{Pt}(\mathrm{en})]^{2+}$ molecular ion causes the separation between the neighboring base pairs to

$2+$

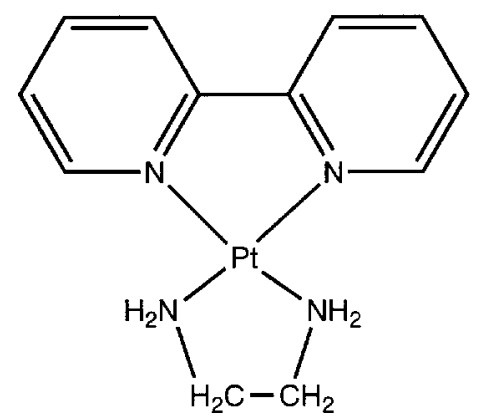

FIG. 1. The bipyridyl-(ethylenediamine)platinum(II) molecular ion (abbreviated as [(bipy) $\operatorname{Pt}($ en $\left.)]^{2+}\right)$. 
double (to $6.8 \AA$ ), yielding a repeat length of $10.2 \AA$ along the helical direction.

$\mathrm{X}$-ray fiber diffraction patterns have provided very useful information about the structure of nucleic acids since the earliest works of Franklin and Gosling, and Wilkins et al. [10-13]. However, the quality of the x-ray diffraction patterns suffers because the samples are not single crystals. Rather, they are composed of crystallites that are uniaxially ordered around the fiber axis. The x-ray diffraction pattern is usually ill defined and does not contain sufficient information to determine the molecular structure uniquely. One must fit the diffraction pattern using simplified structural models that often assume a uniform conformation. In some cases this is known to be an oversimplification [14-16]. An additional complication in the $x$-ray study of the DNA. $[(\text { bipy }) \operatorname{Pt}(\text { en })]^{2+}$ complex is that the platinum of the $[(\text { bipy }) \mathrm{Pt}(\mathrm{en})]^{2+}$ is an efficient scatterer of $\mathrm{x}$ rays due to its very high atomic number. This will greatly affect the observed $x$-ray diffraction pattern from the DNA $\cdot[$ (bipy) Pt(en $)]^{2+}$ complex. Given these uncertainties, it is important to test the ladder model proposed by Arnott et al. [8].

In this paper, we refer to complexes of DNA with $\mathrm{Na}^{+}$ and $[(\text { bipy }) \mathrm{Pt}(\text { en })]^{2+}$ ions as $\mathrm{NaDNA} \cdot[(\text { bipy }) \mathrm{Pt}(\text { en })]^{2+}$. In practice, the relative proportions of $\mathrm{Na}^{+}$and $[(\text { bipy }) \mathrm{Pt}(\mathrm{en})]^{2+}$ ions depend on the preparation conditions, as discussed below.

Isothermal titrational calorimetry (ITC) and infrared (IR) spectroscopy have recently been used by two of the current authors (S.A.L. and A.S.) to study the DNA. [(bipy)Pt(en) $]^{2+}$ complex [17]. The ITC experiments showed that $[\text { (bipy) } \mathrm{Pt}(\mathrm{en})]^{2+}$ binds to DNA in water solution at two independent binding sites. The binding is entropically driven: $+25 \mathrm{cal} / \mathrm{mol} \mathrm{K}$ for the first site and $+22 \mathrm{cal} / \mathrm{mol} \mathrm{K}$ for the second site. The first binding site is filled at about one [(bipy)Pt(en) $]^{2+}$ for every seven base pairs and the second site is filled at a total amount of about one $[(\text { bipy }) \mathrm{Pt}(\mathrm{en})]^{2+}$ for every three base pairs. The binding constants for the first and second sites are $(8.1 \pm 3.1)$ $\times 10^{6} \mathrm{M}^{-1}$ and $(3.7 \pm 0.88) \times 10^{5} \mathrm{M}^{-1}$, respectively. Accounting for differences in electrolytic concentrations, the single binding constant reported by Howe-Grant and Lippard [7] agrees well with an average value for the two actual binding sites. IR experiments were performed on unoriented films with different molar ratios of $[(\text { bipy }) \mathrm{Pt}(\mathrm{en})]^{2+}$ to DNA base pairs (from 0.00 to 0.47 ). The IR data show that the frequencies of the vibrational modes of the DNA are not changed by the binding of $[(\text { bipy }) \mathrm{Pt}(\mathrm{en})]^{2+}$, including the conformationally sensitive modes at about $807,835,895$, 1225 , and $1710 \mathrm{~cm}^{-1}$, to within the uncertainties of the measurements. This suggests that the geometry of the DNA molecule is essentially unaffected by the binding of $[(\text { bipy }) \mathrm{Pt}(\mathrm{en})]^{2+}$, in contradiction with the model of Arnott et al. [8].

In this paper we report our studies of the NaDNA $\cdot[(\text { bipy }) \operatorname{Pt}(\text { en })]^{2+}$ complex using a variety of techniques sensitive to molecular conformation: $x$-ray diffraction, elastic neutron diffraction, two-dimensional magicangle-spinning (MAS) ${ }^{31} \mathrm{P}$ nuclear magnetic resonance (NMR), infrared linear dichroism (LD), unpolarized IR absorption, and mechanochemical techniques. These experiments provide a diverse data set for the NaDNA $\cdot\left[(\text { bipy)Pt(en) }]^{2+}\right.$ complex. As we shall show, our experimental results are inconsistent with several predictions of the ladder model. Rather, our experimental results show that the conformation of the DNA molecule undergoes only a modest change upon attachment by $[(\text { bipy }) \mathrm{Pt}(\mathrm{en})]^{2+}$ : the DNA is essentially in the $B$ conformation but the rise per residue is slightly shortened. This change is most likely caused by the $[(\text { bipy }) \mathrm{Pt}(\mathrm{en})]^{2+}$ binding in one (or both) of the DNA grooves. Our neutron data are consistent with the molecules packing in a centered orthorhombic unit cell with $a=22.65 \AA$ and $b=32.2 \AA$.

$\mathrm{X}$-ray and neutron diffraction techniques have long been used to study the structure of molecules. Magic-anglespinning NMR, IR-LD, and mechanochemistry are less traditional techniques to use in structural studies of macromolecules, but they provide very important complementary information about the structure of DNA. MAS-NMR and IR-LD provide direct information about the orientation of the phosphate group in the phosphodiester backbone. Such information, clearly important for determining a structure, is completely absent from the x-ray and neutron diffraction results. Mechanochemistry experiments provide information about gross changes in geometry due to a conformational transition, or, in this case, the attachment of a ligand. Here we briefly review these "less traditional" techniques.

\section{A. MAS-NMR}

Solid-state NMR is a powerful and widely used method for extracting orientational information from polymers $[18,19] .{ }^{31} \mathrm{P}$ NMR on oriented fibers of DNA has been used to determine the orientation of the backbone phosphate group with respect to the helical axis $[14,20-22]$. This is made possible by assuming that the ${ }^{31} \mathrm{P}$ chemical shift anisotropy (CSA) tensor has a known orientation with respect to the local $\mathrm{PO}_{4}$ symmetry axis. Usually, the ${ }^{31} \mathrm{P}$ CSA orientations determined in the model compound barium diethyl phosphate [23] are used. This assumption is supported by the good agreement between the structural information obtained by solid-state NMR of DNA and the structural models resulting from other methods [14,20,21].

In MAS-NMR, the sample is rotated at several $\mathrm{kHz}$ at an angle of $54.7^{\circ}$ (the "magic angle" at which the width of the solid-state NMR signals is minimized) with respect to the static magnetic field. This technique allows for the extraction of orientational information with particularly good resolution and sensitivity [24]. The NMR spectrum consists of a central peak at the isotropic chemical shift and a number of spinning sidebands separated by the sample rotation frequency $\omega_{r}$ [25]. By synchronizing the sample rotation with the rf pulse scheme, it is possible to extract the orientational distribution functions (ODF's) of the CSA tensors [19,24]. The orientation of the phosphate group is given by the Euler angles $\alpha_{P D}$ and $\beta_{P D}[14,26]$. These angles describe the orientation of the principal axis system of the ${ }^{31} \mathrm{P}$ CSA tensor with respect to the DNA helix axis.

\section{B. Infrared linear dichroism}

Using linearly polarized radiation greatly enhances the information present in an infrared absorption spectrum because 
the absorption amplitude depends on the relative orientation of the transition moment and the electric field. For oriented DNA samples, the absorbances are measured for the IR radiation parallel and perpendicular to the helical axes, $A_{\|}$and $A_{\perp}$, respectively. The dichroic ratio is determined by $R$ $=A_{\perp} / A_{\|}$. Since the pioneering work of Pilet and Brahms [27], IR-LD has been used as a valuable tool for determining the conformation of the DNA molecule itself, and to obtain details of the DNA backbone geometry [28]. Of particular interest to the current study are the angles $\Theta_{\mathrm{OPO}}$ and $\Theta_{\mathrm{OO}}$ which define the orientation of the $\mathrm{PO}_{2}^{-}$moiety relative to the sugar-phosphate backbone of DNA. $\Theta_{\mathrm{OPO}}$ is the angle between the OPO bisector and the helical axis of DNA while $\Theta_{\mathrm{OO}}$ is the angle between the line connecting the two oxygen atoms of the $\mathrm{PO}_{2}^{-}$moiety and the helix axis of DNA; these angles are shown in Fig. 1 of Pohle et al. [29]. (The connection between these angles and the Euler angles used in MASNMR is described in Sec. II below.) $\Theta_{\mathrm{OPO}}$ and $\Theta_{\mathrm{OO}}$ can be determined from the dichroic ratios measured for the bands due to the symmetric and antisymmetric $\mathrm{PO}_{2}^{-}$stretching vibrations, respectively, by applying a suitable orientation function such as the frequently used one described by Fraser [30]. By this algorithm, it became feasible to differentiate the established DNA conformations, not only the canonical $A$ and $B$ forms [27,31], but also the $C$ form $[31,32]$ and $Z$ forms [33].

Systematic comparisons of the phosphate group orientations determined by MAS-NMR, IR-LD, and X-ray experiments have been made for $A-, B$-, and $C$-DNA $[14,29]$. The agreement appears to be adequate and indicates that the error margin is about $5-10^{\circ}$ for IR-LD and about $10-20^{\circ}$ for the other techniques.

Under certain conditions, the IR-LD technique can provide information about the orientation of ligands with respect to the DNA helix axis [34]. This occurs when, in the IR spectra of the complexes, sufficiently strong and well separated IR modes appear due to the ligand, whose transitionmoment directions are generally known; such a case was first realized by DNA-caffeine complexes [35].

\section{Infrared absorption}

Vibrational spectroscopies, such as IR absorption and Raman scattering, can more indirectly provide information about the geometry of the molecule under study because the frequency of the molecular vibrations depends also on the geometric arrangement of the atoms. Each conformation of a molecule will have a distinct vibrational spectrum because of its unique geometry. Conformationally sensitive IR and Raman modes of DNA (believed to be localized within the phosphodiester backbone) have been well characterized for the $A, B$, and $Z$ conformations [36,37].

\section{Mechanochemistry of fibers in ethanolic bath}

The solid samples of oriented DNA.[(bipy)Pt(en) $]^{2+}$ complex studied in the present work were prepared with a wet-spinning method [38,39]. However, the very fibers of oriented DNA precipitated in the ethanolic spinning bath during the spinning process can also be used for mechanochemical studies. In these fibers (which are studied in their ethanolic bath), the DNA molecules are aligned along their helical axis but with a much smaller order in the plane perpendicular to the helical axis than exists in fibers that have passed the drying procedure forming highly crystalline, oriented films. As shown by Rupprecht et al. [40] the relative length of such DNA fibers in ethanolic baths as a function of the concentration of alcohol reveals the $B-A$ transition by a shrinkage of the fiber due to the change in the rise per residue (3.4 $\AA$ for $B$-DNA and $2.6 \AA$ for $A$-DNA) [1]. For a short review, see Piskur and Rupprecht [41]. This technique will be used to detect any changes in length of NaDNA fibers during $[\text { (bipy) } \operatorname{Pt}(\text { en })]^{2+}$ attachment.

\section{MATERIALS AND METHODS}

Highly polymerized salmon testes NaDNA (Fluka) and highly polymerized calf thymus NaDNA (Pharmacia) were used without further purification. $99.5 \%(\mathrm{v} / \mathrm{v})$ ethanol was purchased from Kemetyl AB (Stockholm, Sweden). Bipyridyl-(ethylenediamine)platinum(II) was synthesized as the iodide salt, $[$ (bipy) $\operatorname{Pt}(\mathrm{en})] \mathrm{I}_{2} \quad$ (molecular weight $=665.19 \mathrm{~g} / \mathrm{mol}$ ), via the method of Watt and Upchurch [42].

\section{A. Sample preparation}

The solid, oriented films and the amorphous fibers in ethanolic baths studied in the present work were prepared with a wet-spinning method $[38,39]$ and the $[\text { (bipy)Pt(en) }]^{2+}$ molecular ion was introduced during the bathing procedure to produce the DNA. $[(\text { bipy }) \mathrm{Pt}(\mathrm{en})]^{2+}$ complex. As will be shown below, this experimental protocol produces samples as identical as possible to the complex produced by Arnott et al. [8]. However, it is possible that the complex formed in this manner is different from the complex formed by binding the $[\text { (bipy) } \operatorname{Pt}(\text { en })]^{2+}$ molecular ion to DNA in solution first and then producing oriented films and fibers. Because of this possible complication, our experimental protocol will be explained in full detail.

Spinning Large samples (for MAS-NMR and neutron scattering) were prepared essentially with the following values of the processing variables. A solution of salmon testes NaDNA (1.5 mg NaDNA per $\mathrm{ml}$ in $150 \mathrm{mM} \mathrm{NaCl}$ $+3 \mathrm{~m} M \mathrm{Na}_{3}$-citrate $+0.05 \mathrm{~m} M \mathrm{Na}$-EDTA) is continuously extruded through a spinneret (feed rate $90 \mathrm{~mL} / \mathrm{h}$; glass spinneret from the former firm Paul Aschenbrenner Pan Apparatebau, Mullheim, Germany, with 2000 cylindrical holes each $60 \mu \mathrm{m}$ diam and $2 \mathrm{~mm}$ length) into a spinning bath (75\% ethanol containing about $150 \mathrm{mM} \mathrm{NaCl}$ ) at the top of a glass column. During precipitation, the DNA fibers are stretched as they pass down the column and, via a stationary V-shaped fiber guide, they are converged into a bundle which is wound onto a rotating Teflon-coated glass cylinder (100 $\mathrm{mm}$ diam; speed of rotation $14 \mathrm{rev} / \mathrm{min})$. While rotating, the cylinder also performs a slow axial motion back and forth (axial velocity $2.7 \mathrm{~mm} / \mathrm{min}$ ) within a preset range (determined by the desired width of the film formed later in the drying process), and a deposit of parallel fibers of oriented DNA is built up to desired width and thickness. The spinning of fibers yielding thin films for IR study was modified as described by Rupprecht and Fritzsche [43]. All these samples of salmon testes NaDNA were bathed as described below. The fiber bundle samples of calf thymus NaDNA used for 
the mechanochemical study were taken from an earlier mechanochemical work [40]; see the section "Mechanochemistry of fibers in ethanolic bath" below for the further treatment of these samples.

Bathing. The cylinder with the deposit of parallel fibers of salmon testes NaDNA was bathed for three weeks at room temperature in $65 \%$ ethanol containing $30 \mathrm{mM} \mathrm{NaCl}$ $+2 \mathrm{~m} M \mathrm{Na}_{3}$-citrate and $2.81 \mathrm{~m} M[$ (bipy) $\mathrm{Pt}(\mathrm{en})] \mathrm{I}_{2}$. The amount of bath was adjusted to the amount of DNA so as to correspond to about $1.5[\text { (bipy) } \mathrm{Pt}(\mathrm{en})]^{2+}$ ions per DNA base pair. The spun deposit of DNA fibers on the cylinder quickly became yellowish in color to the naked eye as the $[\text { (bipy) } \mathrm{Pt}(\mathrm{en})]^{2+}$ was absorbed by the DNA but no change in its macroscopic dimensions could be observed. These films are assumed to be saturated with $[(\text { bipy }) \mathrm{Pt}(\mathrm{en})]^{2+}$. Finally, the bath with cylinder was brought to $+5{ }^{\circ} \mathrm{C}$ as a preliminary for the drying procedure.

Drying. The cylinder was placed on a rotating holder (Fig. 8 of Rupprecht [39]) and excess alcohol from the bathing solution was wiped off with a piece of absorbent paper, after which the cylinder was placed in an empty desiccator still at $+5{ }^{\circ} \mathrm{C}$. In one or two days part of the ethanol and water was released from the spun deposit on the cylinder. As a result, the deposit coalesces into a highly oriented film of the DNA $[(\text { bipy }) \mathrm{Pt}(\text { en })]^{2+}$ complex. It is also during this coalescence that microcrystals may form in the film; see, e.g., Rupprecht and Forslind [44] and Rupprecht et al. [45] for $\mathrm{x}$-ray diffraction patterns of various wet-spun DNA films. If necessary, the drying process can be speeded up by adding a small amount of silica gel to the desiccator. The liquid that had condensed on the desiccator walls was wiped off and a beaker with saturated $\mathrm{NaCl}$ solution $\left(+5^{\circ} \mathrm{C}\right)$ was placed in the desiccator which was brought to room temperature. After storage for one day over the saturated $\mathrm{NaCl}$ solution, the film of DNA. $\left[(\text { bipy) } \operatorname{Pt}(\text { en })]^{2+}\right.$ (about $30 \mathrm{~cm}$ long) was released from the cylinder by cutting across it with a razor blade.

The amount of $[\text { (bipy) } \mathrm{Pt}(\mathrm{en})]^{2+}$ absorbed by these "saturated" films was determined by two different methods. One technique was to measure the optical absorption of the bathing solution before and after the bathing procedure, and use the fact that $[($ bipy $) \mathrm{Pt}(\mathrm{en})] \mathrm{I}_{2}$ in an ethanolic solution has an absorbance maximum at $318.8 \mathrm{~nm}$ with an extinction coefficient $\varepsilon_{318.8}=1900 \mathrm{M}^{-1} \mathrm{~cm}^{-1}$. The second technique was to use atomic emission spectroscopy on small pieces of the wet-spun films. An Iris Advantage instrument from Thermo Jarrell Ash was used to perform atomic emission spectroscopy (AES) experiments with an inductively coupled argon plasma. Chemical decomposition of the test samples (40-50 $\mathrm{mg}$ ) was done by adding $3 \mathrm{ml} \mathrm{HNO}_{3}(65 \%)$ and 3 $\mathrm{ml} \mathrm{H}_{2} \mathrm{O}_{2}(30 \%)$ and heating by microwave. The observed weight percentages for $\mathrm{Na}(2.5 \pm 0.1), \mathrm{P}(5.6 \pm 0.2)$, and Pt $(9.0 \pm 0.3)$ in the NaDNA. [( bipy) Pt(en $)]^{2+}$ film are based on three measurements. These experiments showed that the sample contained one $[(\text { bipy }) \operatorname{Pt}(\mathrm{en})]^{2+}$ ion per every $1.96 \pm 0.09$ base pairs, corresponding to a molar ratio (of $[\text { (bipy) } \mathrm{Pt}(\mathrm{en})]^{2+}$ to DNA base pairs) equal to $0.51 \pm 0.02$. The optical absorption measurements yielded the same molar ratio (0.50). All of our samples have this molar ratio except for one sample with less $[\text { (bipy) } \mathrm{Pt}(\mathrm{en})]^{2+}$, as described in the next paragraph.
One sample was prepared in a manner to have less than the "saturated" amount of $[\text { (bipy) } \mathrm{Pt}(\text { en })]^{2+}$. First, a deposit of parallel "saturated" DNA. [(bipy)Pt(en) $]^{2+}$ fibers was produced by the usual bathing procedure (i.e., bathing the DNA fibers in $65 \%$ ethanol containing $30 \mathrm{mM} \mathrm{NaCl}$ $+2 \mathrm{mM} \mathrm{Na}{ }_{3}$-citrate and $2.81 \mathrm{~m} M[$ (bipy) $\mathrm{Pt}(\mathrm{en})] \mathrm{I}_{2}$ for three weeks). The cylinder with the deposit was then rinsed twice in an ethanolic bath with no $[(\text { bipy }) \mathrm{Pt}(\mathrm{en})]^{2+}$ and finally bathed in another ethanolic bath with no [(bipy) $\mathrm{Pt}(\mathrm{en})]^{2+}$ for ten days. Afterward, the fibers were dried via the usual procedure to produce the highly crystalline, wet-spun film. The amount of $[(\text { bipy }) \mathrm{Pt}(\mathrm{en})]^{2+}$ in this sample was determined by the same two methods described above (optical absorption and atomic emission spectroscopy). By monitoring the optical absorption of the rinsing and bathing solutions during this procedure, the molar ratio of the final film was determined to be 0.33 . AES experiments were also performed on this film and yielded a molar ratio of $0.32 \pm 0.01$.

The conversion of these films and fibers into samples for the various methods of study is described below under the methods' headings.

\section{B. X-ray diffraction}

About $0.3 \mathrm{~mm}$ thick samples were prepared with a folding apparatus [39] and mounted in the spring-loaded sample holder shown in Fig. 1 of Rupprecht and Forslind [44]. After storage for one day at $75 \%$ relative humidity $(\mathrm{RH})$ (over a saturated $\mathrm{NaCl}$ solution at $23^{\circ} \mathrm{C}$ ), the sample in its holder (still at $75 \% \mathrm{RH}$ ) was mounted perpendicularly to the central beam in a wide-angle x-ray camera. Nickel-filtered $\mathrm{Cu} K_{\alpha}$ radiation was used with a collimator of $500 \mu \mathrm{m}$. The sample-to-film distance was $51.4 \mathrm{~mm}$ and the exposure time was usually $2 \mathrm{~h}$. Even the thin films used for the IR experiments could be folded into an X-ray sample, partly by folding it together with the Teflon carrier film of an $8 \mathrm{~cm}$ long strip prepared as described under "IR techniques" below.

$\mathrm{X}$-ray diffraction experiments were also performed on two fiber bundles (one of pure NaDNA and the other of the NaDNA $\cdot\left[(\text { bipy)Pt(en) }]^{2+}\right.$ complex) which had not yet undergone the drying procedure (fibers similar to those used in the mechanochemistry experiments). These fibers were prepared by spinning a thick and narrow strip of DNA fibers on the smallest cylinder available ( $29 \mathrm{~mm}$ diam). A $1 \mathrm{~cm}$ long piece of the specially spun, thick and narrow fiber strip was pushed into a $1.5 \mathrm{~mm}$ diameter Debye-Scherrer capillary tube filled with the appropriate $65 \%$ ethanol bathing solution. The bathing solution contained $2.81 \mathrm{mM}$ $[($ bipy $) \mathrm{Pt}($ en $)] \mathrm{I}_{2}$ for the NaDNA $\left[(\text { bipy) } \mathrm{Pt}(\text { en })]^{2+}\right.$ complex and no $[(\text { bipy }) \operatorname{Pt}(\text { en })]^{2+}$ for the pure NaDNA sample. These operations were performed in the bath. After sealing the capillary with Parafilm, it was glued to the plate of the $\mathrm{x}$-ray holder. As a result the sample-to-film distance became a little shorter, about $49.4 \mathrm{~mm}$. The same procedure was used for the pure DNA fibers in the $65 \%$ ethanol. The water content of these DNA fibers should be quite high. From an x-ray diffraction study of DNA fibers equilibrated at a certain RH and in ethanol-water solutions, Wyckoff [46] found that $85 \%$ ethanol is roughly equivalent to $75 \% \mathrm{RH}$ and that $70 \%$ ethanol is roughly equivalent to $92 \% \mathrm{RH}$. Roughly extrapolat- 
ing, we estimate that the $65 \%$ ethanol used here should be equivalent to about $97 \% \mathrm{RH}$ or to an approximate water content of the DNA fibers of about 80 water molecules per base pair [47].

\section{Neutron scattering}

Two large NaDNA. $\left[(\text { bipy)Pt(en) }]^{2+}\right.$ films (width 40 $\mathrm{mm}$, thickness $65 \mu \mathrm{m}$ ) were folded separately by hand into two concertinalike packs each containing seven layers of film. The end folds of the packs were pushed into each other yielding a single sample with 14 film layers, which was slightly compressed. It had the approximate dimensions 40 $\times 40 \times 0.91 \mathrm{~mm}^{3}$ and weighed about $2.12 \mathrm{~g}$ at $75 \% \mathrm{RH}$. This pack was then inserted into a flat $\mathrm{Al}$ container whose lid was sealed by In wire. In order to avoid possible electrochemical reaction of the sample with the $\mathrm{Al}$ container, two thin $\mathrm{Nb}$ sheets $(0.1 \mathrm{~mm}$ thick) were added to cover the large surfaces.

Structural information complementary to the x-ray diffraction data was obtained by mounting this sample on a neutron three-axis spectrometer set to elastic scattering (within about $1 \mathrm{meV}$ ). Neutrons of $2.35 \AA$ wavelength filtered by pyrolytic graphite were used. The sample plate was mounted upright with the average helical direction within the horizontal scattering plane. The scattering angle of the spectrometer and rotation of the sample around the vertical axis were then automatically varied over a mesh of $59 \times 57$ points covering momentum (or wave vector) transfers $0.28 \AA^{-1}$ $\leqslant Q_{\|} \leqslant 2.6 \AA^{-1}$ and $-1.4 \AA^{-1} \leqslant Q_{\perp} \leqslant 1.4 \AA^{-1}$, respectively. $Q_{\|}$and $Q_{\perp}$ denote the components of the momentum transfer parallel and perpendicular to the helical axis of the sample, respectively. Additional data were taken with a finer step width $\left(0.01 \AA^{-1}\right)$. Data were also taken for $0.10 \AA^{-1}$ $\leqslant Q_{\perp} \leqslant 1.2 \AA^{-1}$ and $Q_{\|}=0.0 \AA^{-1}$.

After recording this intensity map the sample chamber was opened and the DNA pack exposed to dry silica gel for 3 days, thereby losing $0.44 \mathrm{~g}$ water. Thereafter the sample was stored over a saturated solution of $\mathrm{NaClO}_{3}$ in $\mathrm{D}_{2} \mathrm{O}$. After a period of 30 days the sample had reached a weight of $2.13 \mathrm{~g}$ corresponding to a water uptake of $0.45 \mathrm{~g}$. The sample chamber was sealed again and the corresponding map for humidification with $\mathrm{D}_{2} \mathrm{O}$ was measured.

\section{MAS-NMR}

The films of NaDNA $[\text { (bipy)Pt(en) }]^{2+}$ complex (width $10 \mathrm{~mm}$, thickness $50 \mu \mathrm{m}$ ) or LiDNA (width $11 \mathrm{~mm}$, thickness $45 \mu \mathrm{m}$ ) were folded back and forth in a folding apparatus [39] to form a concertinalike pack. These packets were slightly compressed and placed between the parallel plates of a spring-loaded holder [39]. To help the film layers in each packet stick together, the holder was kept at somewhat higher RH (78-83\% RH) for a few days and then returned to $75 \% \mathrm{RH}$. The resulting samples had the approximate dimensions $2 \times 2 \times 10\left(\mathrm{NaDNA} \cdot[(\text { bipy }) \mathrm{Pt}(\mathrm{en})]^{2+}\right)$ and 2.5 $\times 2.5 \times 11 \mathrm{~mm}^{3}$ (LiDNA).

The DNA samples were wrapped in plastic foil (polyethene) to retain humidity, and mounted in $\mathrm{ZrO}_{2}$ rotors with the fibers perpendicular to the magic-angle spinning axis. The rotors were of outer diameter $4 \mathrm{~mm}$ (Bruker) for NaDNA. [(bipy)Pt(en) $]^{2+}$ and $6 \mathrm{~mm}$ (Chemagnetics) for LiDNA. The remaining space in the rotors was filled with

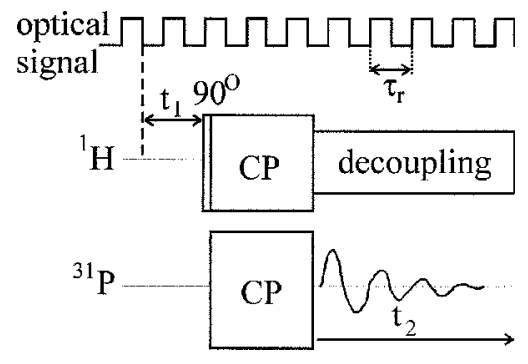

FIG. 2. The rotor-synchronized 2D MAS experiment.

$\mathrm{Al}_{2} \mathrm{O}_{3}$ powder for mechanical balance and sample fixing. The rotor was spun at $2000 \pm 2 \mathrm{~Hz}$, at the magic angle $\left(54.7^{\circ}\right)$ to the static magnetic field. The experiments were performed at a ${ }^{31} \mathrm{P}$ Larmor frequency $\omega_{0} / 2 \pi=$ -81.04 MHz [48] with a 4.7 T magnetic field on a Chemagnetics CMX Infinity NMR system. The rotor-synchronized cross-polarization magic-angle-spinning (CP-MAS) experiment of Harbison and Spiess [24] (see Fig. 2) was used to acquire a two-dimensional (2D), $16 \times 1024$ point data set, which was Fourier transformed and phase adjusted to zeroth and first order in both dimensions. The proton $90^{\circ}$ pulse duration was typically $4 \mu \mathrm{s}$, the $\mathrm{CP}$ contact time was 1-2 $\mathrm{ms}$, and each signal transient was of duration 15-20 ms. As a check, additional experiments at a spinning frequency of $2.6 \mathrm{kHz}$ were done for LiDNA, yielding very similar results to those at $2 \mathrm{kHz}$ (data not shown). All experiments were done at room temperature. The signals from 128 to 256 experimental transients were summed for each value of $t_{1}$ to achieve an adequate signal-to-noise ratio.

\section{E. MAS-NMR data analysis}

The integrated spinning sideband intensities of the 2D spectra $S\left(\omega_{1}, \omega_{2}\right)$ were analyzed using CSA values determined by MAS experiments on randomly oriented LiDNA fibers ( $\left.\delta_{\text {aniso }}=-92.5 \mathrm{ppm}, \eta=0.64\right)$. Here the principal values of the chemical shift tensor (deshielding convention) are arranged $\left|\delta_{z z}-\delta_{i s o}\right|>\left|\delta_{y y}-\delta_{i s o}\right| \geqslant\left|\delta_{x x}-\delta_{i s o}\right|$, where $\delta_{i s o}$ $=\left(\delta_{x x}+\delta_{y y}+\delta_{z z}\right) / 3$, and $\delta_{\text {aniso }}=\delta_{z z}-\delta_{\text {iso }}$ and $\eta=\left(\delta_{y y}\right.$ $\left.-\delta_{x x}\right) / \delta_{\text {aniso }}$. The phosphate ODF was derived as a function of the Euler angles $\alpha_{P D}$ and $\beta_{P D}$, using an analysis method closely following that given by Harbison et al. [49]. The angles $\left(\alpha_{P D}, \beta_{P D}\right)$ describe the orientation of the principal axis system (PAS) P of the ${ }^{31} \mathrm{P}$ CSA tensor, with respect to the director frame $D$ defined by the average direction of the DNA fiber long axes. In the fitting procedure, spherical harmonics $Y_{q}^{L}\left(\beta_{P D}, \alpha_{P D}\right)$ of even rank $0 \leqslant L \leqslant L_{\max }$ are superimposed (only even ranks are involved due to the bipolarity of DNA) with their amplitudes adjusted in order to obtain the best fit between experimental sideband intensities and their calculated values. In order to assess the sensitivity of the analysis with respect to the assumed CSA principal values, we repeated the analysis for NaDNA $\cdot[\text { (bipy)Pt(en) }]^{2+}$ using CSA values from randomly oriented NaDNA netropsin films, which are in the $B$ form, prepared in the same way ( $\delta_{\text {aniso }}=-93.9 \mathrm{ppm}, \eta=0.65$ ). No appreciable differences could be seen in the resulting ODF's (data not shown).

The NMR data analysis estimates the angles $\alpha_{P D}$ and $\beta_{P D}$, which relate the principal axis system of the ${ }^{31} \mathrm{P}$ chemical shift tensor to the fiber director. To convert these 
data into molecular structural information, one must make assumptions about (i) the orientation of the ${ }^{31} \mathrm{P}$ chemical shift tensor with respect to the local symmetry axes of the phosphate group, and (ii) the orientation of the helix long axes with respect to the fiber director. A local molecular frame for the phosphate group, $M$, is defined as follows: $\mathbf{x}_{M}$ is perpendicular to the $\mathrm{O}^{\prime}{ }^{\prime}-\mathrm{P}-\mathrm{O} 2^{\prime}$ plane, and points toward the $\mathrm{O}^{\prime}$ oxygen. $\mathbf{y}_{M}$ bisects the $\mathrm{O}^{\prime}{ }^{\prime}-\mathrm{P}-\mathrm{O} 2^{\prime}$ plane, pointing from the phosphorus toward $\mathrm{O}^{\prime}{ }^{\prime}$ and $\mathrm{O} 2^{\prime}$. $\mathbf{z}_{M}$ is perpendicular to $\mathbf{x}_{M}$ and $\mathbf{y}_{M}$, forming a right-handed coordinate system. The ${ }^{31} \mathrm{P}$ CSA principal axes for the model compound barium diethyl phosphate were found to be about $10^{\circ}$ away from the corresponding axes of the $M$ system [23]. We assume that the $P$ and $M$ frames coincide in DNA with about the same level of accuracy. In addition, we assume that the fiber director, which defines the $\mathbf{z}_{D}$ axis of the fiber director frame $D$, coincides perfectly with the helix axis of every DNA molecule, which defines the $\mathbf{z}_{H}$ axis of the helix frame $H$. With these assumptions, the angles $\alpha_{P D}$ and $\beta_{P D}$, as identified by the NMR measurements, are expected to coincide with the structurally significant angles $\alpha_{M H}$ and $\beta_{M H}$, to within around $10-20^{\circ}$

\section{F. IR techniques}

The NaDNA $\cdot[(\text { bipy }) \operatorname{Pt}(\text { en })]^{2+}$ film on the spinning cylinder was secured to the underlying Teflon carrier film with pieces of tape as illustrated in Fig. 2 of Rupprecht and Fritzsche [43]. The tape with underlying carrier film and surrounding carrier film was cut through with a razor blade (dashed lines in the figure) releasing a strip of carrier film with $\mathrm{NaDNA} \cdot\left[(\text { bipy) } \mathrm{Pt}(\mathrm{en})]^{2+}\right.$ film attached. Using the procedure described by Rupprecht and Fritzsche [43] the film was transferred from the Teflon carrier film to a midIR-transparent window made of ZnSe (Vitron, Jena). This sample window was mounted into a specially designed modified gas cell and investigated further in situ. IR spectra were recorded by co-adding 16 scans with a resolution of $4 \mathrm{~cm}^{-1}$ by a Fourier-transform Galaxy 4020 spectrometer from Mattson, Madison (Wisconsin), equipped with a $\mathrm{ZnSe}$ polarizer, for relative humidities from $44 \%$ to $98 \%$. All the details concerning experimental procedure and the estimation of the characteristic phosphate angles according to the IR-LD algorithm of Fraser [30] were the same as reported previously $[29,50]$. The dichroic ratios $R$ (defined as $\left.A_{\perp} / A_{\|}\right)$ are correlated with the $\Theta$ angles by a function additionally involving the orientation parameter $f[30]$; $f$ has to be estimated on the basis of data other than those from IR-LD [29]. The angles $\Theta_{\mathrm{OO}}$ and $\Theta_{\mathrm{OPO}}$ are related to the Euler angles $\alpha_{M H}$ and $\beta_{M H}$ (defined in the "MAS-NMR data analysis section" above $)$ via $\Theta_{\mathrm{OO}}=\beta_{M H}$ and $\cos \left(\Theta_{\mathrm{OPO}}\right)$ $=\sin \left(\alpha_{M H}\right) \sin \left(\beta_{M H}\right)$. Processing and analysis of the rough spectroscopic data were done using the FIRST software provided by Mattson.

\section{G. Mechanochemistry of fibers in ethanolic bath}

The simple mechanochemical setup, that was used for the measurements consists of a $14 \mathrm{~mm}$ diameter measuring cylinder containing the bath and supplied inside with a glass hook positioned at the upper index of the measuring cylinder scale. The DNA fiber bundle hangs down from the glass hook and is held straight by a $10 \mathrm{mg} \mathrm{V}$-shaped Pt weight at its lower end. The $\mathrm{Pt}$ weight also serves as a marker for reading off the position of the lower end of the fiber bundle on the measuring cylinder scale; see Fig. 2 of Song et al. [51]. The DNA fiber bundle was mounted by winding its ends a few turns around the glass hook and the Pt weight, respectively, with the aid of a pair of tweezers. These operations were performed in an ethanolic bath by analogy with the procedure described by Rupprecht [52]; see, in particular, Fig. 2 of that article.

First, the sample was placed in a measuring cylinder containing $68 \%$ ethanol $+30 \mathrm{~m} M \mathrm{NaCl}+2 \mathrm{~m} M \mathrm{Na}_{3}$-citrate. This ethanol concentration was chosen as a compromise to retain mechanical strength of the fibers and yet stay with the DNA mainly in the $B$ form; see Figs. 4(a) and 4(b) and Table II of Rupprecht et al. [40]. After equilibration, the reference length of the fiber bundle, $L_{0}$, was determined (typically 130 $\mathrm{mm})$. Then the fiber bundle was carefully lifted up and placed in a measuring cylinder with the same ethanolic bath but also containing $3.37 \mathrm{~m} M[$ (bipy) $\operatorname{Pt}($ en $)] \mathrm{I}_{2}$. During one experiment, the DNA. [(bipy)Pt(en) $]^{2+}$ fiber bundle was brought back to the original ethanolic bath free of $[\text { (bipy) } \mathrm{Pt}(\mathrm{en})]^{2+}$. During all these operations the length of the fiber bundle, $L$, was measured to provide information about structural changes. The water content of the DNA fibers in $68 \%$ ethanol is rather high, about 50 water molecules per base pair, as estimated from the data of Wyckoff [46] and Lindsay et al. [47].

\section{RESULTS AND DISCUSSION}

\section{A. X-ray diffraction}

Figure 3(a) shows the x-ray diffraction pattern obtained from a polycrystalline, wet-spun film of $\mathrm{NaDNA} \cdot[\text { (bipy)Pt(en) }]^{2+}$ at $75 \% \mathrm{RH}$. This pattern is very similar to those reported by Arnott et al. [8] and Lippard et al. [5], clearly showing that our experimental protocol has produced the same complex as reported in those papers. As mentioned in Sec. II, the molar ratio of $[\text { (bipy) } \mathrm{Pt}(\text { en })]^{2+}$ to DNA of this sample was determined to be 0.50 , consistent with the X-ray evidence of a nearest neighbor exclusion rule reported by Arnott et al. [8] and Lippard et al. [5].

The ITC results of Szabó et al. [17] show that $[$ (bipy)Pt(en $)]^{2+}$ binds to DNA via two independent sites which are essentially fully occupied by a molar ratio of about 0.33. A wet-spun film was prepared with a molar ratio of 0.33 and the diffraction pattern from this film is shown in Fig. 3(b). This pattern is identical to Fig. 3(a), showing that the NaDNA $\cdot[\text { (bipy) Pt(en) }]^{2+}$ complex is fully formed with one $[\text { (bipy) } \mathrm{Pt}(\text { en })]^{2+}$ molecular ion for every three DNA base pairs. This observation is in contrast to the predictions of the ladder model, which requires a molar ratio of 0.50 . The $10.2 \AA$ spacing observed in this complex is due to the spacing of the $[\text { (bipy) } \mathrm{Pt}(\text { en })]^{2+}$ ligands along the DNA molecule: one for every three base pairs.

There is no evidence that the $[(\text { bipy }) \mathrm{Pt}(\mathrm{en})]^{2+}$ molecular ions that attach to the $\mathrm{NaDNA} \cdot[\text { ( bipy) } \mathrm{Pt}(\text { en })]^{2+}$ complex between molar ratios of 0.33 and 0.50 affect the conformation of the complex in any significant manner. This observation is consistent with the results of Szabó et al. [17] who found by ITC that these $[(\text { bipy }) \operatorname{Pt}(\text { en })]^{2+}$ molecular ions are 


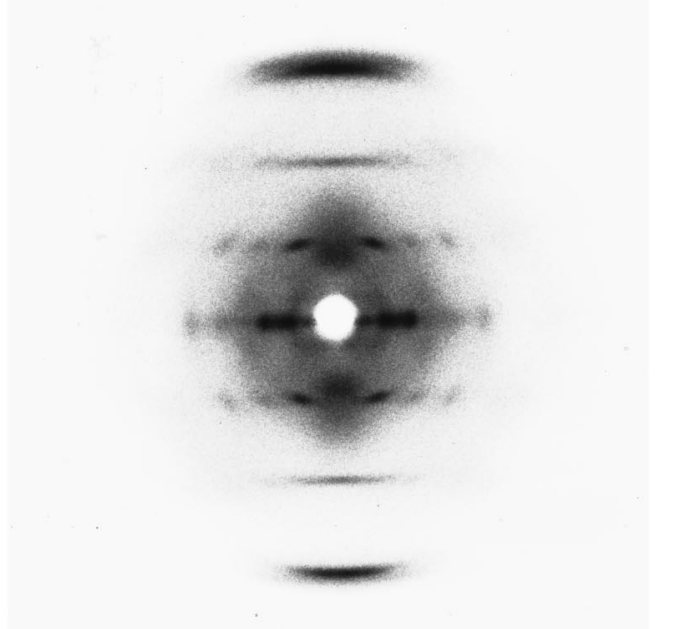

(a)

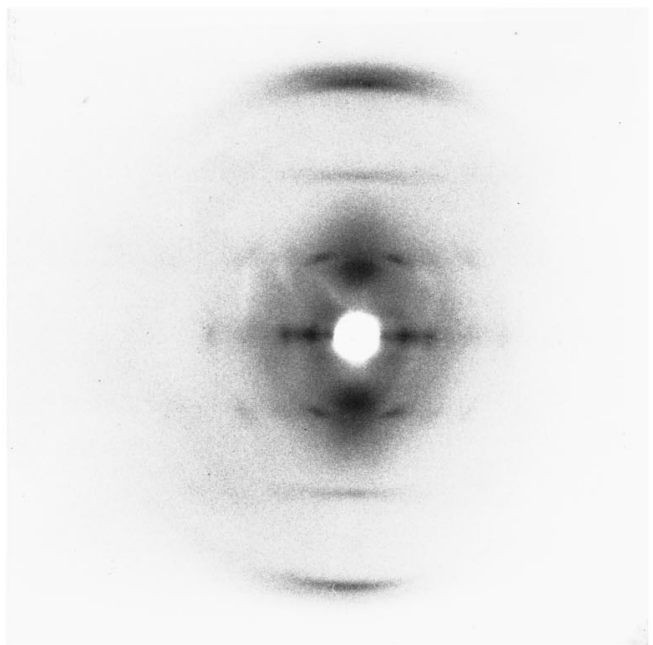

(b)

FIG. 3. X-ray diffraction pattern of a solid film of oriented NaDNA. $[\text { (bipy)Pt(en) }]^{2+}$ complex prepared with a wet-spinning method from salmon testes NaDNA with a molar ratio of $\left[(\text { bipy) } \mathrm{Pt}(\mathrm{en})]^{2+}\right.$ to DNA base pairs of (a) 0.50 and (b) 0.33 . The RH was $75 \%$.

bound very weakly. These $[(\text { bipy }) \mathrm{Pt}(\mathrm{en})]^{2+}$ molecular ions are believed to attach to the complex in essentially a random manner since their presence does not change the observed $\mathrm{x}$-ray diffraction pattern.

\section{B. Neutron scattering}

Figure 4 shows the map of elastic neutron scattering intensity observed from the NaDNA $[\text { (bipy) } \mathrm{Pt}(\mathrm{en})]^{2+}$ complex at $75 \% \mathrm{RH}\left(\mathrm{H}_{2} \mathrm{O}\right)$ for momentum transfers $0.28 \AA^{-1}$ $\leqslant Q_{\|} \leqslant 2.6 \AA^{-1}$ and $-1.4 \AA^{-1} \leqslant Q_{\perp} \leqslant 1.4 \AA^{-1}$, respectively. This figure exhibits several peaks due to distinct density correlations (i.e., periodic distances within the sample) on top of a smoothly varying distribution due to the dominating self-correlation of the hydrogen atoms in the sample. The latter contribution represents the Debye-Waller factor for the hydrogen atoms together with the effect of selfabsorption of the flat sample and is of minor interest in the present context.

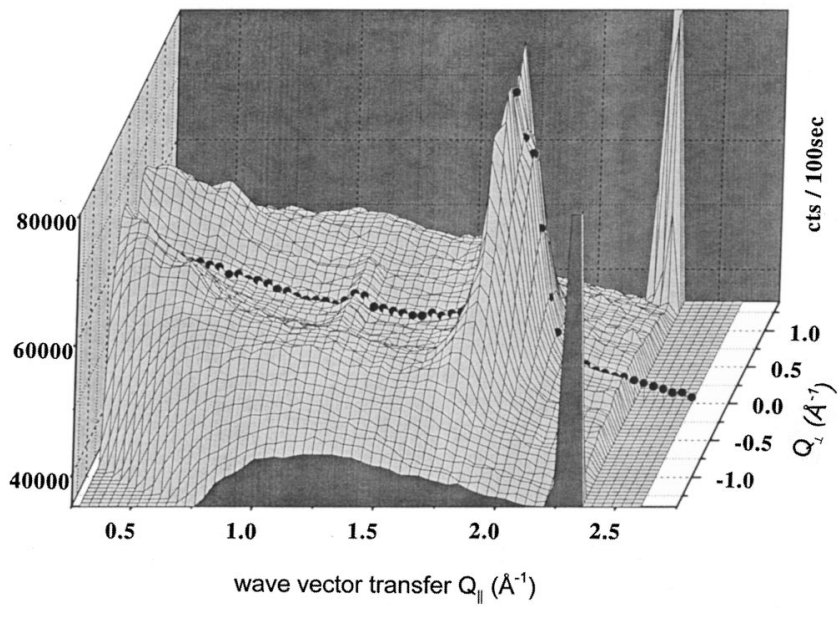

FIG. 4. Map of elastic neutron diffraction intensity for NaDNA complexed with [(bipy) $\operatorname{Pt}($ en $)]^{2+}\left(0.50\right.$ molar ratio). $Q_{\|}$and $Q_{\perp}$ denote the components of the momentum transfer parallel and perpendicular to the helical axis of the sample, respectively. The sharp peaks at $Q_{\|} \cong 2.3 \AA^{-1}, Q_{\perp} \cong \pm 1.4 \AA^{-1}$ arise from the DebyeScherrer ring $\mathrm{Al}(111)$ of the sample container. The remainder of this intensity has been omitted for clarity of presentation. The dotted curve corresponds to the meridional scan shown in Fig. 5 below. The sample was hydrated to $75 \% \mathrm{RH}\left(\mathrm{H}_{2} \mathrm{O}\right)$.

The dominant feature of the data in Fig. 4 is a strong meridional feature near $Q_{\|} \cong 1.86 \AA^{-1}$. This peak is broad, with appreciable intensity in the range $-0.75 \AA^{-1}<Q_{\perp}<$ $+0.75 \AA^{-1}$. A much weaker meridional peak is observed at about $Q_{\|}=1.22 \pm 0.02 \AA^{-1}$. This peak is also broad, with appreciable intensity in the range $-0.45 \AA^{-1}<Q_{\perp}<$ $+0.45 \AA^{-1}$. Even weaker off-meridional peaks are present at about $Q_{\|}=0.61 \pm 0.02 \AA^{-1}$ and $Q_{\perp}=0.35 \pm 0.02 \AA^{-1}$. To facilitate the discussion of these data, Fig. 5 shows the $Q_{\perp}$ $=0.0 \AA^{-1}$ slice of the data. The solid black-filled circles connected by the solid line in Fig. 5 correspond to the solid black-filled circles in Fig. 4; that is, NaDNA $\cdot[\text { (bipy) } \mathrm{Pt}(\text { en })]^{2+}$ hydrated to $75 \%$ RH with $\mathrm{H}_{2} \mathrm{O}$. The empty circles connected by the solid line in Fig. 5 are the data from NaDNA. [(bipy)Pt(en) $]^{2+}$ hydrated to $75 \%$ $\mathrm{RH}$ with $\mathrm{D}_{2} \mathrm{O}$. Two other sets of data (also taken from wetspun films at 75\% RH) are shown in Fig. 5. The dashed line shows the data obtained from pure NaDNA and the gray area shows the data from LiDNA with a high content of LiCl. Wet-spun films of NaDNA at 75\% RH are known to be in an admixture of the $A$ and $B$ conformations while wet-spun films of LiDNA with a high content of $\mathrm{LiCl}$ are known to be purely in the $B$ conformation. (see data in Table I and Brandes et al. [53]). Since the rise per residue $d_{b p}$ for $A$ - and $B$-DNA is 2.56 and $3.38 \AA$, respectively, a peak is expected at 2.45 and $1.86 \AA^{-1}$, respectively $\left(Q_{\|}=2 \pi / d_{b p}\right)$. The peaks associated with these two conformations are labeled in Fig. 5 at their respective positions. As expected, the data for the pure NaDNA show peaks for both the $A$ and $B$ conformations while the data for LiDNA show the peak associated with the $B$ conformation only. Examining the data from the NaDNA $\cdot[(\text { bipy }) \operatorname{Pt}(\text { en })]^{2+}$ complex, it is immediately apparent that the presence of the $[\text { (bipy) } \mathrm{Pt}(\mathrm{en})]^{2+}$ compound completely suppresses the $A$ conformation. The inset of Fig. 5 shows data taken near $1.86 \AA^{-1}$ with a smaller step width. 


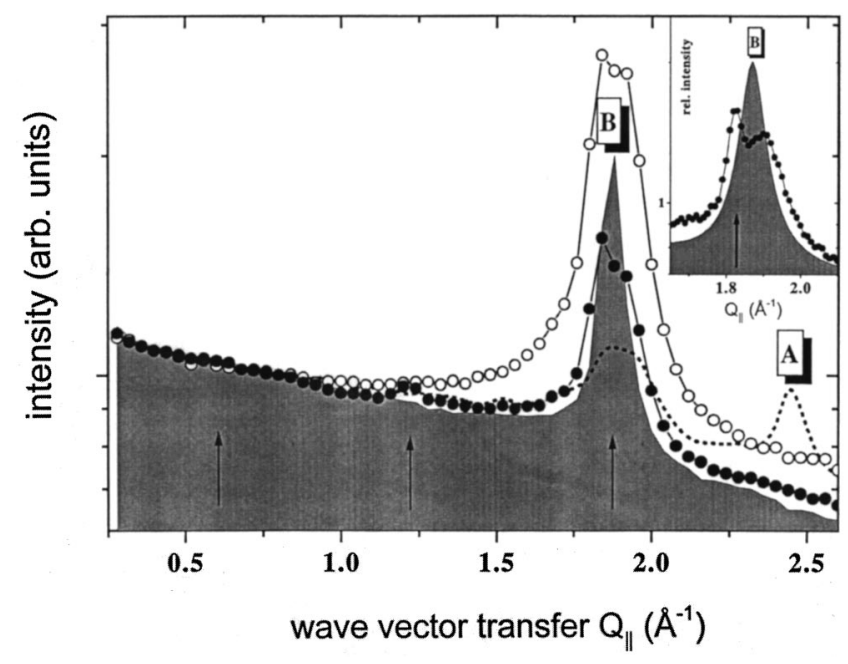

FIG. 5. Comparison of four meridional scans at $75 \% \mathrm{RH}$. The scans have been normalized to $Q_{\|}=0.64 \AA^{-1}$. The gray area graph represents the normal neutron diffraction intensity of the $B$ conformation (wet-spun film of LiDNA with a large excess of $\mathrm{LiCl}$ ). The dashed line shows the neutron diffraction intensity from a wet-spun film of NaDNA. The circles connected by the solid lines show the neutron diffraction intensity for the NaDNA. [(bipy)Pt(en) $]^{2+}$ complex (filled circles for $\mathrm{H}_{2} \mathrm{O}$ hydration and open circles for $\mathrm{D}_{2} \mathrm{O}$ hydration). The labels $A$ and $B$ indicate the location of the peaks due to diffraction from the rise per residue for the $A$ and $B$ conformations, respectively. The inset shows data taken near $1.86 \AA^{-1}$ with a smaller step width: filled circles connected by a solid line for the NaDNA. $[(\text { bipy }) \mathrm{Pt}(\mathrm{en})]^{2+}$ complex and the gray area for LiDNA (which is in the $B$ conformation). Most pure NaDNA samples show an admixture of the $A$ and $B$ conformations under these conditions, as observed here. The arrows at 1.22 and $1.82 \AA^{-1}$ mark the peaks that are harmonics of the $0.61 \AA^{-1}$ offmeridional peak (see Fig. 4).
The data from the NaDNA.[(bipy)Pt(en) $]^{2+}$ complex (filled circles with solid line) clearly show a doublet in this region at $Q_{\|}=1.820 \pm 0.05$ and $1.90 \pm 0.01 \AA^{-1}$. Data from LiDNA (which is in the $B$ conformation) are shown by the gray filled line. These data reveal that the DNA of the $\mathrm{NaDNA} \cdot\left[(\text { bipy)Pt(en) }]^{2+}\right.$ complex is in the $B$ conformation.

The weak off-meridional peak at $Q_{\|}=0.61 \AA^{-1}$ provides evidence that the distance of $10.3 \AA$ along the helical axis corresponds to a periodicity within the $\mathrm{NaDNA} \cdot\left[(\text { bipy) } \operatorname{Pt}(\mathrm{en})]^{2+}\right.$ complex. This is in good agreement with the $10.2 \AA$ spacing reported by the x-ray studies of Arnott et al. [8] and Lippard et al. [5]. Sufficient lateral order can cause enhancement of the off-meridional intensity and diminution of the meridional intensity.

Further evidence for the $10.3 \AA$ spacing is found in the presence of the $Q_{\|}=1.22$ and $1.82 \AA^{-1}$ peaks, which are harmonics of the $0.61 \AA^{-1}$ peak. On the basis of these three peaks, the periodicity along the helical axis is 10.35 $\pm 0.05 \AA$. As described above, this periodicity reflects the presence of one $[\text { (bipy) } \operatorname{Pt}(\text { en })]^{2+}$ ion for every three DNA base pairs.

The $Q_{\|}=1.90 \AA^{-1}$ peak is believed to be due to the rise per residue (i.e., the distance between base pairs along the helical axis). The spacing corresponding to this momentum transfer is $3.31 \AA$, which shows that the DNA is in a "distorted" $B$ conformation (recall that the expected rise per residue of $B$-DNA is $3.38 \AA$ ). It should be noted that this rise per residue is almost the same as that observed from $C$-DNA (3.29 $\AA$ ).

Crystalline samples of noninteracting DNA would be expected to adopt a hexagonal unit cell. However, intermolecular interactions between neighboring DNA molecules lower the symmetry of the crystalline solids: the $B$ and $C$ conformations are described by a centered orthorhombic cell [54].

TABLE I. Characteristic $\Theta_{\mathrm{OO}}$ and $\Theta_{\mathrm{OPO}}$ angles (and the corresponding Euler angles $\alpha_{M H}$ and $\beta_{M H}$ ) of DNA in different samples including hand-stroked and wet-spun films (the former giving rise to the values published previously, cf. Table III in Pohle et al. [29] and the latter used in the present paper) and wet-spun films of the DNA. $\left[(\text { bipy)Pt(en) }]^{2+}\right.$ complex together with the DNA conformations determined from the data. Recall that the Euler angles $\alpha_{M H}$ and $\beta_{M H}$ available from the IR-LD data are believed to be the same as the Euler angles $\alpha_{P D}$ and $\beta_{P D}$ determined by MAS-NMR to within $10^{\circ}-20^{\circ}$.

\begin{tabular}{lcccccc}
\hline \hline Sample & $\mathrm{RH}(\%)$ & $\Theta_{\mathrm{OO}}\left({ }^{\circ}\right)^{\mathrm{a}}$ & $\Theta_{\mathrm{OPO}}\left({ }^{\circ}\right)^{\mathrm{a}}$ & $\alpha_{M H}\left({ }^{\circ}\right)^{\mathrm{a}}$ & $\beta_{M H}\left({ }^{\circ}\right)^{\mathrm{a}}$ & Conformation \\
\hline$B$-DNA & $>92$ & $52-55^{\mathrm{b}}$ & $62-65^{\mathrm{b}}$ & $37-31$ & $52-55$ & $B$ \\
$A$-DNA & $59-84$ & $59-64^{\mathrm{b}}$ & $46-50^{\mathrm{b}}$ & $54-46$ & $59-64$ & $A$ \\
$C$-DNA & $44-75$ & $48-50^{\mathrm{c}}$ & $61-64^{\mathrm{c}}$ & $41-35$ & $48-50$ & $C$ \\
\hline DNA $^{\mathrm{d}}$ & 98 & 56 & 65 & 31 & 56 & $B$ \\
& $59-44$ & 58 & 55 & 43 & 58 & $A / B^{\mathrm{e}}$ \\
DNA·[(bipy)Pt(en) $]^{2+}$ & $88-98$ & 55 & 65 & 31 & 56 & $\mathrm{~B}$ \\
& $59-75$ & 55 & 63.5 & 33 & 55 & $\mathrm{~B}$ \\
\hline \hline
\end{tabular}

${ }^{\mathrm{a}}$ Error bars of these figures are $\pm 5^{\circ}-10^{\circ}$ and better.

bAverage values for eukaryotic NaDNA's of different origin measured as hand-stroked films with practically ideal (i.e., 100\%) conformational flexibility (cf. Pohle et al. [29]).

${ }^{c}$ Obtained for LiDNA.

${ }^{\mathrm{d}}$ Wet-spun salmon sperm DNA as used in this study.

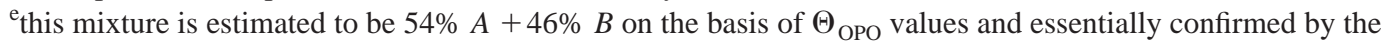
$A / B$ fractions that can be ascertained from the relative absorbances of the $A$ and $B$ marker bands near 860 and $835 \mathrm{~cm}^{-1}[57,62]$. 


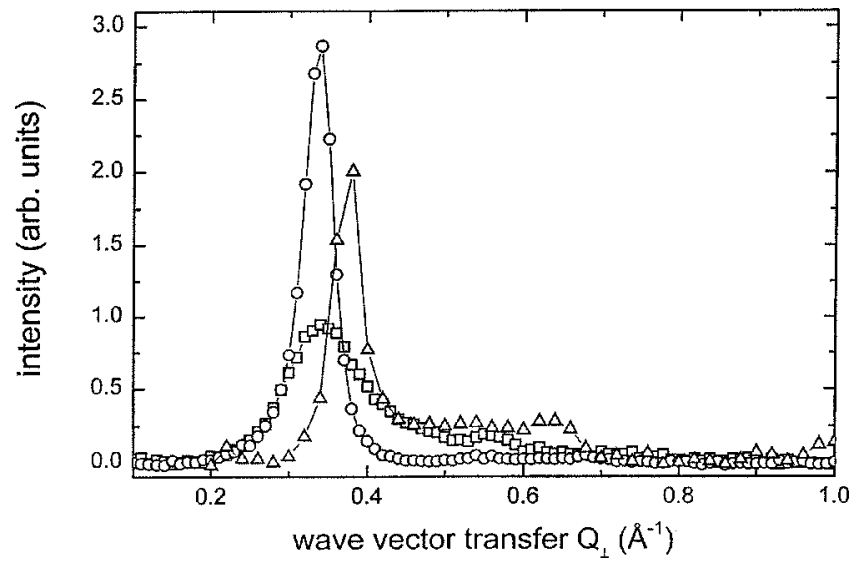

FIG. 6. Neutron diffraction data for momentum transfers $Q_{\|}$ $=0.0 \AA^{-1}$ and $0.10 \AA^{-1}<Q_{\perp}<+1.0 \AA^{-1}$ for wet-spun films of $\mathrm{NaDNA} \cdot[\text { (bipy)Pt(en) }]^{2+}$ (open squares connected by solid line) and of pure LiDNA in both the $B$ (open circles connected by solid line) and $C$ (open triangles connected by solid line) conformations. The samples were hydrated to $75 \% \mathrm{RH}$.

The deviation of the $b / a$ ratio from $3^{1 / 2}$ indicates the degree of distortion of the lattice and is characterized by $\rho$ $=b /\left(3^{1 / 2} a\right)$. Figure 6 shows neutron scattering data for momentum transfers $Q_{\|}=0.0 \AA^{-1}$ and $0.10 \AA^{-1} \leqslant Q_{\perp} \leqslant$ $+1.2 \AA^{-1}$ for wet-spun films of NaDNA. [( bipy)Pt(en) $]^{2+}$ and of pure LiDNA in both the $B$ and $C$ conformations. The intense peak observed between 0.3 and $0.4 \AA^{-1}$ for all three samples corresponds to the (110) reflection for each sample. Experiments were performed using both $\mathrm{H}_{2} \mathrm{O}$ and $\mathrm{D}_{2} \mathrm{O}$ for hydration. The difference in scattering lengths for hydrogen and deuterium affects the relative intensities of the diffraction peaks, as shown in Fig. 7. These results indicate that the NaDNA $[(\text { bipy }) \operatorname{Pt}(\text { en })]^{2+}$ molecules pack in a centered orthorhombic cell, as is found for both $B$ - and $C$-DNA. From these data, $a$ is determined to be $22.65,22.9$, and $20.1 \AA$ for

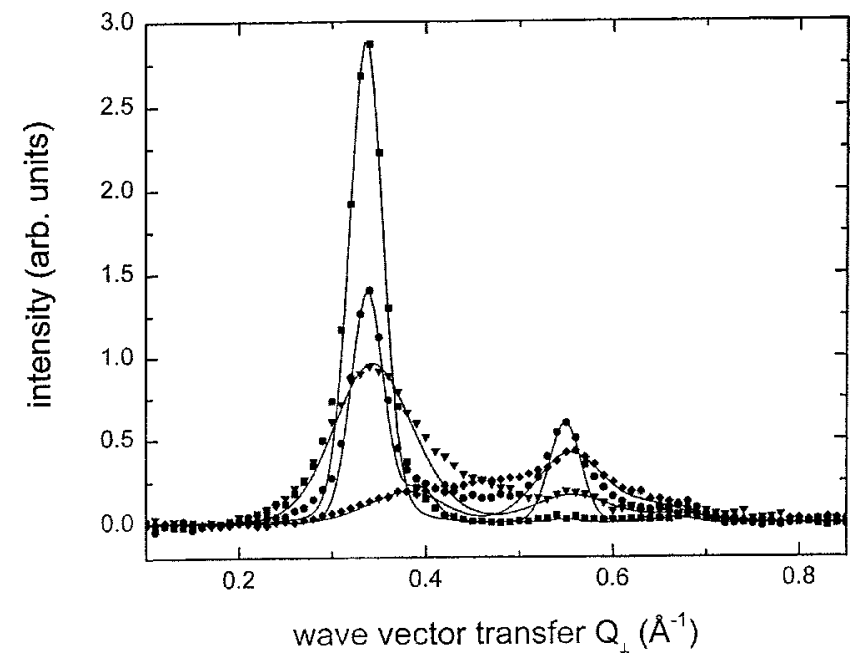

FIG. 7. Neutron diffraction data for momentum transfers $Q_{\|}$ $=0.0 \AA^{-1}$ and $0.10 \AA^{-1}<Q_{\perp}<+0.85 \AA^{-1}$ for wet-spun films of $\mathrm{NaDNA} \cdot[\text { (bipy) Pt(en) }]^{2+}$ hydrated with $\mathrm{H}_{2} \mathrm{O}$ (triangles) and $\mathrm{D}_{2} \mathrm{O}$ (diamonds) and of pure LiDNA in the $B$ conformation hydrated with $\mathrm{H}_{2} \mathrm{O}$ (squares) and $\mathrm{D}_{2} \mathrm{O}$ (circles). The solid lines show the fits to four different data sets based on a centered orthorhombic unit cell. The samples were hydrated to $75 \% \mathrm{RH}$.

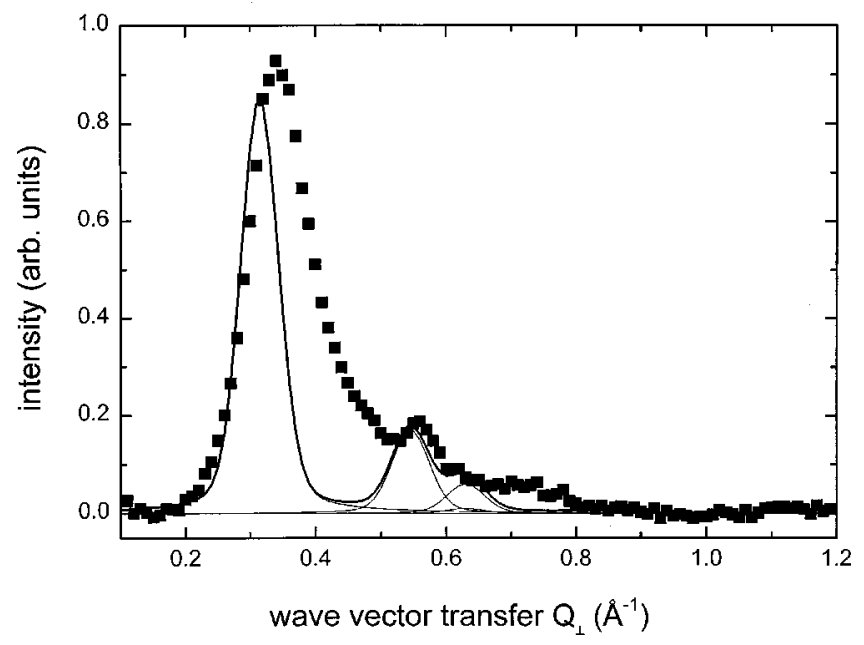

FIG. 8. Neutron diffraction data for momentum transfers $Q_{\|}$ $=0.0 \AA^{-1}$ and $0.10 \AA^{-1}<Q_{\perp}<+1.2 \AA^{-1}$ for wet-spun films of NaDNA $\cdot[\text { (bipy) } \mathrm{Pt}(\text { en })]^{2+}$ hydrated to $75 \% \mathrm{RH}$ with $\mathrm{H}_{2} \mathrm{O}$ (circles) and the predicted diffraction based on the model of Arnott et al. [8] (solid line).

NaDNA $\cdot[(\text { bipy }) \mathrm{Pt}(\text { en })]^{2+}, B$-DNA, and $C$-DNA, respectively, while the corresponding values of $\rho$ are $0.82,0.81$, and 0.92 .

These neutron scattering data are compared to the predictions of the model of Arnott et al. [8] in Fig. 8. The agreement between the data and the model is rather poor, particularly with regard to the position of the most intense feature. The comparison between the experimental data and our orthorhombic model displayed in Fig. 9 shows substantially better agreement. It should be noted that our model fails to account for all of the scattering observed near $0.5 \AA^{-1}$. This discrepancy was also observed in our experiments with $B$-DNA and is believed to be due to inelastic neutron scattering from low frequency modes and/or the low energy tails

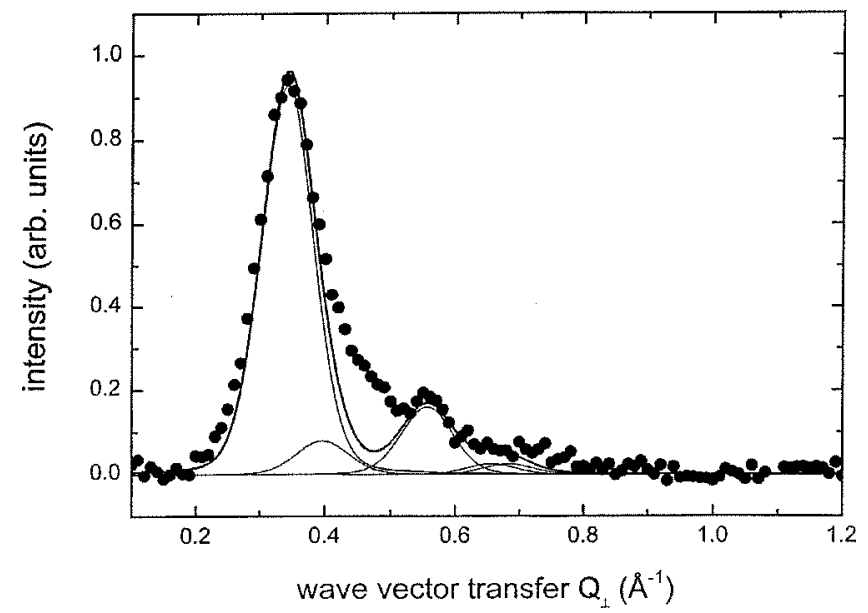

FIG. 9. Neutron diffraction data for momentum transfers $Q_{\|}$ $=0.0 \AA^{-1}$ and $0.10 \AA^{-1}<Q_{\perp}<+1.2 \AA^{-1}$ for wet-spun films of NaDNA $\cdot[\text { (bipy) } \mathrm{Pt}(\text { en })]^{2+}$ hydrated with $\mathrm{H}_{2} \mathrm{O}$ to $75 \%$ RH (circles) and the predicted diffraction based on a centered orthorhombic unit cell (solid line). The extra intensity observed near about $0.5 \AA^{-1}$ is believed to be due to inelastic neutron scattering from low frequency modes and/or the low energy tails as a consequence of anharmonicity. 
as a consequence of anharmonicity.

The observed diffraction peaks for the perpendicular direction from the NaDNA. $[(\text { bipy }) \mathrm{Pt}(\mathrm{en})]^{2+}$ complex are very broad, roughly three times wider than the corresponding peaks from either $B$ - or $C$-DNA. The corresponding lateral correlation length would be as small as the next neighbor distance between molecules. This large fluctuation of the distances between molecules might result from a random bending of the helical axis, possibly related to the attachment of the $[\text { (bipy) } \operatorname{Pt}(\text { en })]^{2+}$ molecular ions.

The lateral dimensions of the unit cell might be affected by the attachment of $[\text { (bipy) } \operatorname{Pt}(\text { en })]^{2+}$, particularly if the binding site is on the "exterior" of the DNA molecule. It is of interest to note that $a$ is smaller for $C$-DNA than for $B$-DNA (20.1 and $22.9 \AA$, respectively). This is consistent with the fact that $C$-DNA has a tighter helical pitch (i.e., shorter rise per residue) than $B$-DNA; the more tightly wound helices can pack more tightly in the unit cell. Based on this reasoning, $a$ for NaDNA $\cdot[\text { (bipy) } \mathrm{Pt}(\text { en })]^{2+}$ would be expected to be about $20.7 \AA$ rather than the observed $22.65 \AA$. This suggests that neighboring DNA molecules in the NaDNA. $[(\text { bipy }) \operatorname{Pt}(\text { en })]^{2+}$ samples are about $2 \AA$ farther apart than expected. On the other hand, the $b$ dimension of the unit cell is 32.2, 32.2, and $32.0 \AA$ for $\mathrm{NaDNA} \cdot\left[(\text { bipy) } \mathrm{Pt}(\mathrm{en})]^{2+}, B\right.$-DNA, and $C$-DNA, respectively, showing no effect related to the ligand.

The dimension of the unit cell in the helical direction is unclear since the first-layer line is not detected in the x-ray data. Given that our data suggest that the double helix is in a "distorted" $B$ conformation close to the $C$ conformation, comparisons to those two conformations should yield useful information about the $c$ dimension. Assuming 10 base pairs per helical turn ( $B$-DNA) yields $c=33.1 \AA$ while $28 / 3$ base pairs per helical turn ( $C$-DNA) yields $c=30.9 \AA$.

\section{MAS-NMR}

Figure 10 shows the two-dimensional MAS-NMR data at $75 \%$ RH. The spectra show spinning sidebands along the $\omega_{2}$ axis and resolution of sidebands representing molecular order along the $\omega_{1}$ axis. Figure 11 shows the resulting experimental distribution of the $\alpha_{P D}$ and $\beta_{P D}$ angles for a $\mathrm{NaDNA} \cdot\left[(\text { bipy) } \mathrm{Pt}(\text { en })]^{2+}\right.$ sample and a LiDNA sample in the $B$ conformation (both at $75 \% \mathrm{RH}$ ). These plots employ a superposition of spherical harmonics up to and including rank $L_{\max }=10$. Both plots display two peaks, one centered at about $\beta_{P D} \approx 59^{\circ}, \alpha_{P D}=0^{\circ}$ (corresponding to $\Theta_{\mathrm{OO}}=59^{\circ}$, $\Theta_{\mathrm{OPO}}=90^{\circ}$ ) and the other at about $\beta_{P D} \approx 22^{\circ}, \alpha_{P D}=0^{\circ}$ (corresponding to $\Theta_{\mathrm{OO}}=22^{\circ}, \Theta_{\mathrm{OPO}}=90^{\circ}$ ). The $\mathrm{PO}_{4} \mathrm{ODF}$ for $\mathrm{NaDNA} \cdot[\text { (bipy) } \mathrm{Pt}(\mathrm{en})]^{2+}$ is very similar to that for LiDNA; the latter clearly shows the $B$-form x-ray pattern at the relative humidity of $75 \%$ (x-ray data of LiDNA not shown; see Lindsay et al. [47]). The similarity of these two ODF's is very strong evidence that the DNA of the $\mathrm{NaDNA} \cdot[\text { (bipy) } \mathrm{Pt}(\text { en })]^{2+}$ complex is in the $B$ conformation at $75 \% \mathrm{RH}$.

The splitting of the ODF into two components has previously been reported by some of the current authors (Z.S., A.R., and M.H.L.) for $C$-form Li- and MgDNA samples in Ref. [14], which employed the same experimental and fitting procedures. In a forthcoming paper [16], the peak in the

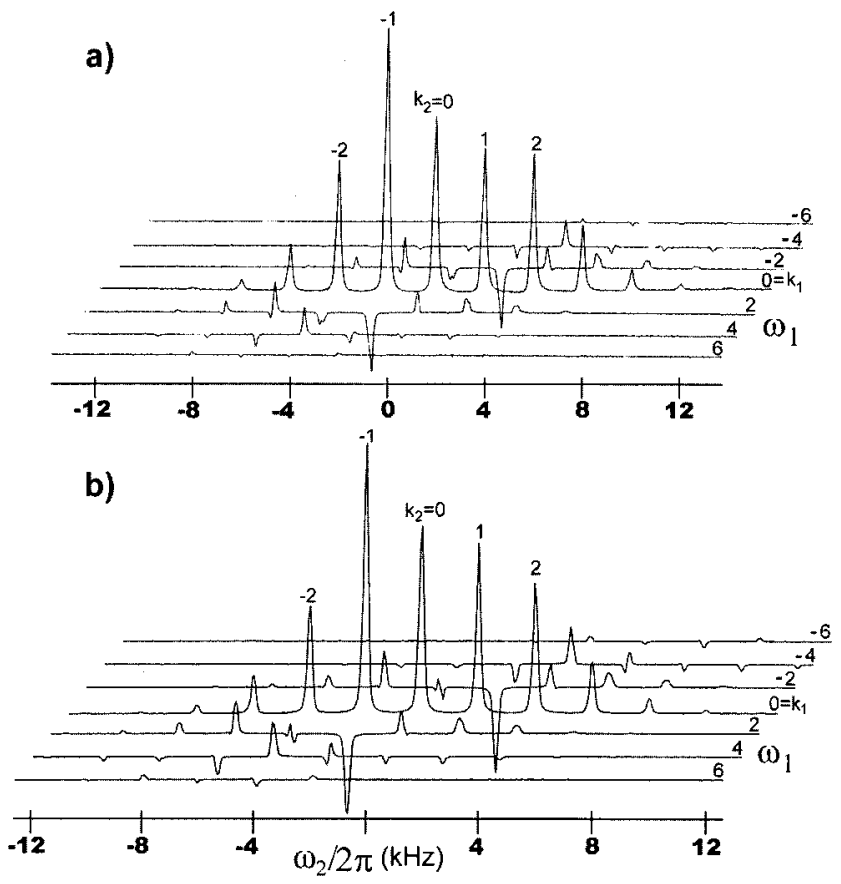

FIG. $10 .{ }^{31} \mathrm{P}$ NMR spectra $S\left(\omega_{1}, \omega_{2}\right)$ from the rotorsynchronized 2D MAS experiment on (a) NaDNA $\cdot\left[(\text { bipy) } \mathrm{Pt}(\text { en })]^{2+}\right.$ at $75 \% \mathrm{RH}$ and 0.50 molar ratio and (b) LiDNA at $75 \%$ RH. $\omega_{1}$ is the rotor-synchronization dimension corresponding to $t_{1}$ in the time domain. The separation between adjacent peaks (sidebands) in the $\omega_{2}$ dimension is $\omega / 2 \pi=2000 \mathrm{~Hz}$, the rotor spinning frequency, for both samples. Indices for the peaks, $k_{1}$ and $k_{2}$, are indicated. For details, see Song et al. [14].

ODF at $\left(\alpha_{P D}, \beta_{P D}\right)=\left(0^{\circ}, 59^{\circ}\right)$ is attributed to nucleotides in the $B$-I conformation, while the peak at $\left(\alpha_{P D}, \beta_{P D}\right)$ $=\left(0^{\circ}, 22^{\circ}\right)$ is attributed to nucleotides in the $B$-II conformation, where the designations $B$-I and $B$-II are described by Grzeskowiak et al. [55]. The presence of both $B$-I and $B$-II conformations in native DNA films has also been detected by infrared spectroscopy [15]. Figure 11 shows that the ratio of $B$-I to $B$-II conformations is remarkably similar for LiDNA and the NaDNA $\cdot[\text { (bipy)Pt(en) }]^{2+}$ complex at $75 \% \mathrm{RH}$.

A previous investigation on the intercalator proflavine [56] showed dramatic differences between the ${ }^{31} \mathrm{P}$ ODF of the DNA - proflavine complex and that of $B$-form DNA: The phosphate ODF was found to split into two strong components with coordinates $\left(\alpha_{P D}, \beta_{P D}\right)=\left(0^{\circ}, 0^{\circ}\right)$ and $\left(0^{\circ}, 90^{\circ}\right)$. Intercalating $[\text { (bipy) } \mathrm{Pt}(\mathrm{en})]^{2+}$ into DNA would be expected to have a similar effect on the phosphate groups. Indeed, the ladder model of Arnott et al. [8] predicts that half of the phosphate groups will have one orientation and the other half will have a different orientation. Thus, the ladder model of the DNA $\cdot[(\text { bipy }) \mathrm{Pt}(\mathrm{en})]^{2+}$ complex predicts that the MAS ${ }^{31} \mathrm{P}$ NMR ODF should have two peaks of equal intensity. This is clearly inconsistent with our observations, shown in Fig. 11.

Figure 12 shows the most probable phosphate-group orientations with respect to the helical axis for the major and minor peaks in the NaDNA. [(bipy)Pt(en) $]^{2+}$ complex, based on the MAS ${ }^{31} \mathrm{P}$ NMR data and under the assumption that the ${ }^{31} \mathrm{P}$ CSA PAS perfectly coincides with the local phosphate symmetry axes. 

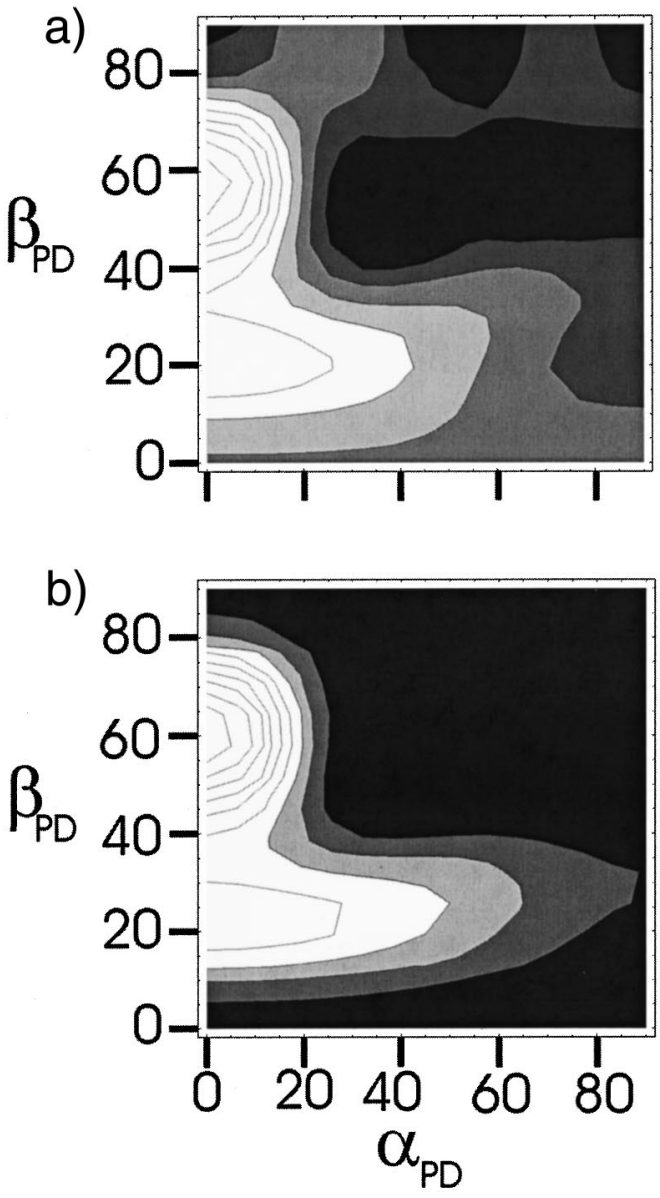

FIG. 11. The phosphate orientational distribution functions in terms of the Euler angles $\alpha_{P D}$ and $\beta_{P D}$ for (a) NaDNA. [(bipy)Pt(en) $]^{2+}$ at $75 \% \mathrm{RH}$, (b) LiDNA (in the $B$ conformation) at $75 \% \mathrm{RH}$. The spinning speed was $2.000 \mathrm{kHz}$ for both samples.

\section{IR techniques}

Figure 13 shows the unpolarized Fourier transform IR (FTIR) spectra of polycrystalline, wet-spun films (at 75\% RH) of the NaDNA. [(bipy)Pt(en) $]^{2+}$ complex and of pure NaDNA as well as a spectrum of $[($ bipy $) \mathrm{Pt}(\mathrm{en})] \mathrm{I}_{2}$ in a pressed $\mathrm{KBr}$ disk. This figure shows that the spectrum of the NaDNA. $[(\text { bipy }) \operatorname{Pt}(\text { en })]^{2+}$ complex is clearly dominated by the bands from DNA - in spite of the rather high fraction of ligand involved (a molar ratio of 0.50 , one $[(\text { bipy }) \mathrm{Pt}(\mathrm{en})]^{2+}$ for every two base pairs). This is of practical convenience since it allows the unambiguous evaluation of the DNA conformation according to a proven procedure already used earlier [29]. Only few absorptions of $[(\text { bipy }) \mathrm{Pt}(\mathrm{en})]^{2+}$ are evident in the spectrum of the complex, most clearly at 1450 , 1050, and $770 \mathrm{~cm}^{-1}$ (as marked by the arrows in Fig. 13). In the following, the dichroic behavior of the most indicative bands of both DNA and ligand will be used to determine the DNA conformation and ligand orientation, respectively.

Figure 14 displays the polarized spectra of NaDNA and the NaDNA. $[(\text { bipy }) \operatorname{Pt}(\text { en })]^{2+}$ complex measured at $75 \%$ RH in each case. Under these conditions of water activity, the $A$ form usually prevails in ordered samples of pure NaDNA $[10,27,29]$, although some $B$-DNA may be present in such samples as well [53]. In Table I, typical $\Theta_{\mathrm{OPO}}$ and a)

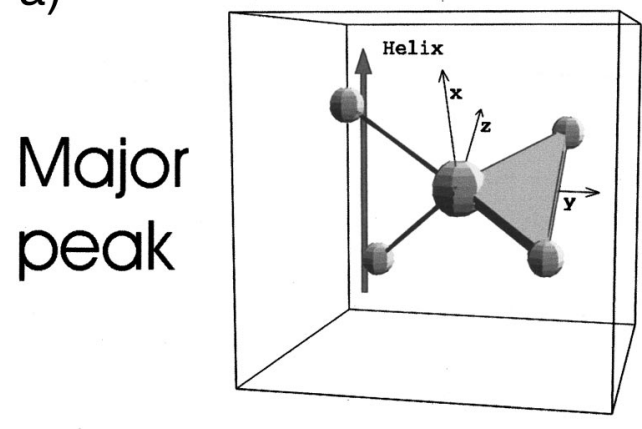

b)

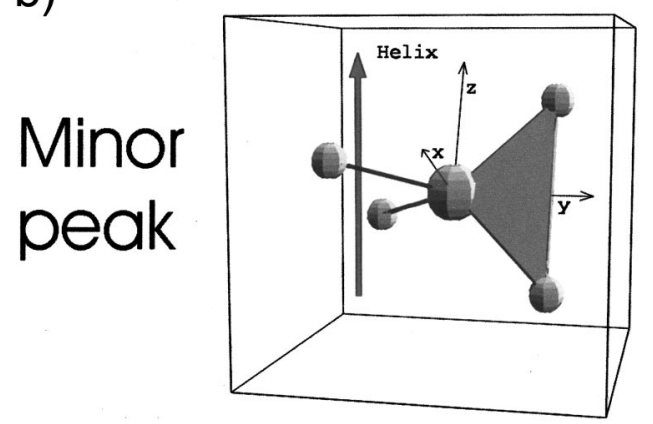

FIG. 12. The most probable orientations of the phosphate groups for the major and minor peaks, respectively, relative to the DNA helix axis for NaDNA-[( bipy)Pt(en) $]^{2+}$. The $\mathrm{O}^{\prime}{ }^{\prime}-\mathrm{P}-\mathrm{O} 2{ }^{\prime}$ plane is shown as a wedge and the attached axis system corresponds to the assumed orientations of the ${ }^{31} \mathrm{P}$ CSA principal axes.

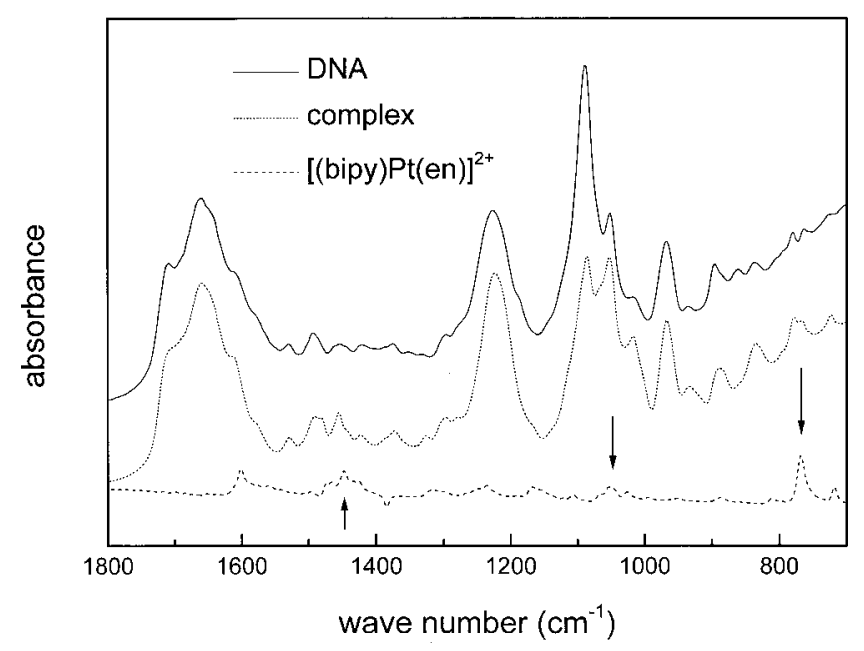

FIG. 13. Unpolarized FTIR spectra between 600 and $1800 \mathrm{~cm}^{-1}$ of an oriented film of salmon sperm NaDNA (solid line on top), an oriented film of salmon sperm NaDNA $\cdot[\text { (bipy) Pt(en) }]^{2+}$ complex with a molar ratio of 0.50 (dotted line in middle), and [(bipy) $\mathrm{Pt}(\mathrm{en})] \mathrm{I}_{2}$ in $\mathrm{KBr}$ disk (dashed line on bottom). The arrows in the spectrum for $[\text { (bipy)Pt(en) }]^{2+}$ indicate the IR bands of $[(\text { bipy }) \operatorname{Pt}(\text { en })]^{2+}$ that are evident in the spectrum from the NaDNA. $[(\text { bipy }) \operatorname{Pt}(\text { en })]^{2+}$ complex. Spectra of samples containing DNA were obtained at $75 \%$ RH. Vertical offsets added to spectra for clarity. 

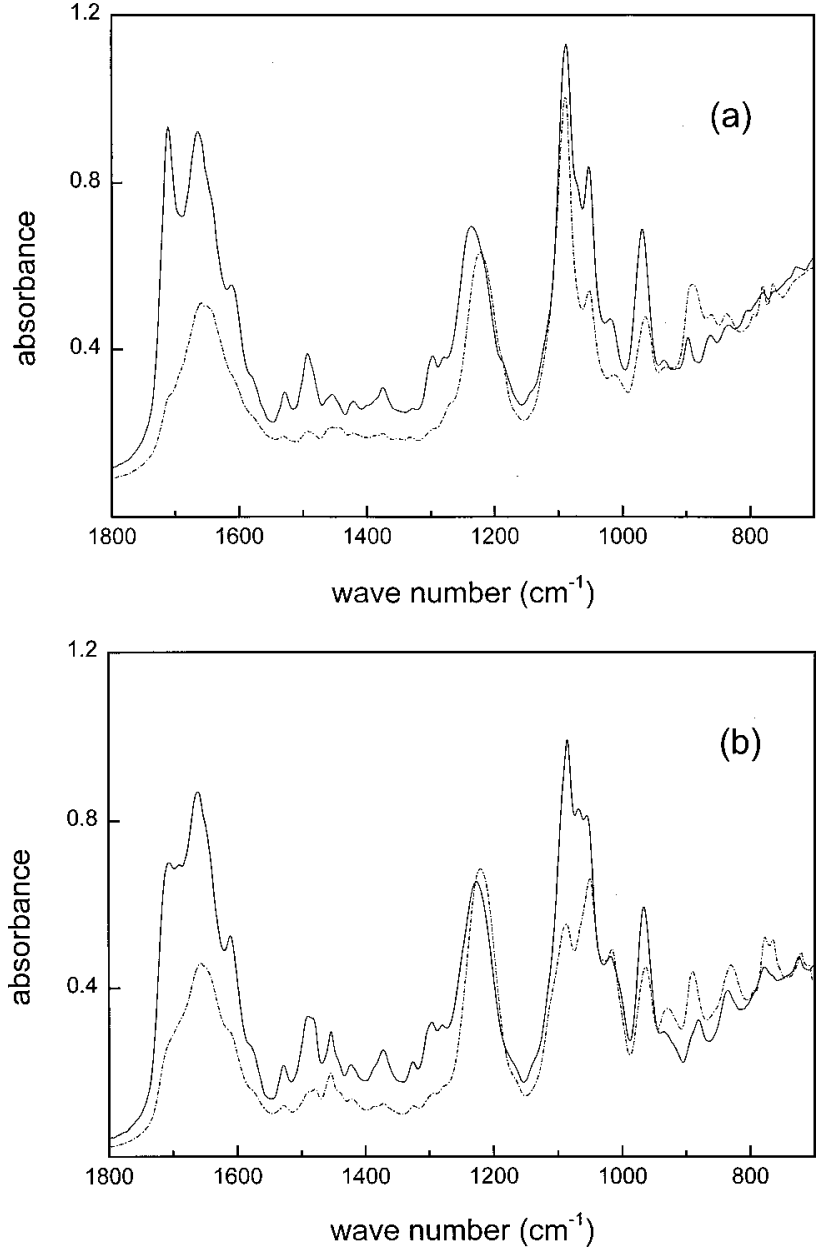

FIG. 14. Polarized FTIR spectra between 600 and $1800 \mathrm{~cm}^{-1}$ recorded at $75 \% \mathrm{RH}$ for oriented films of (a) pure salmon sperm NaDNA and (b) the NaDNA. [( bipy)Pt(en) $]^{2+}$ complex; solid and dash-dotted lines correspond to the spectra obtained with the electric vector of the polarized light perpendicular and parallel to the orientation direction of the sample (i.e., the helical direction of the DNA molecules), respectively.

$\Theta_{\mathrm{OO}}$ angles (as well as the corresponding Euler angles $\alpha_{M H}$ and $\beta_{M H}$ ) for $A$ - and $B$-DNA (from Pohle et al. [29]) are listed together with the results obtained in this study. The results for the NaDNA·[(bipy)Pt(en) $]^{2+}$ complex clearly show that the DNA molecule is in the $B$ conformation for all the values of RH explored.

For pure NaDNA, a significant fraction of the sample (as high as $50 \%$, line 4 and footnote e of Table I) would be in the $A$ conformation at such a low level of water activity $[10,27,29]$. This shows that the $[(\text { bipy }) \operatorname{Pt}(\mathrm{en})]^{2+}$ molecular ion strongly suppresses the formation of the $A$ conformation of DNA. Such strong suppression of the conformational flexibility of DNA is found with strongly bound ligands, such as anthracyclines and netropsin [50,57-59]. This suggests that $[\text { (bipy) } \operatorname{Pt}(\mathrm{en})]^{2+}$ binds strongly to DNA.

An analysis of the dichroic behavior of the $\left[(\text { bipy) } \mathrm{Pt}(\mathrm{en})]^{2+}\right.$ bands visible in the complex (see Fig. 13) is hampered by the fact that these bands are not clearly separated from DNA absorption, rendering a determination of the dichroic ratios of these characteristic $[(\text { bipy }) \operatorname{Pt}(e n)]^{2+}$ bands extremely difficult. Moreover, conclusions to be

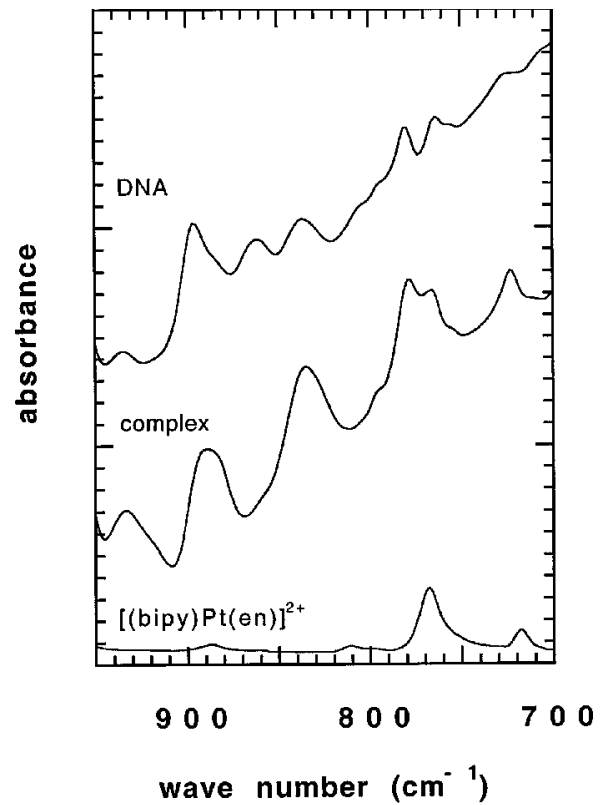

FIG. 15. Unpolarized FTIR spectra between 700 and $950 \mathrm{~cm}^{-1}$ of an oriented film of salmon sperm NaDNA (top line), an oriented film of salmon sperm NaDNA. [(bipy)Pt(en) $]^{2+}$ complex with a molar ratio of 0.50 (middle line), and $[$ (bipy) $\mathrm{Pt}($ en $)] \mathrm{I}_{2}$ in a $\mathrm{KBr}$ disk (bottom line). Spectra of samples containing DNA were obtained at $75 \% \mathrm{RH}$. Vertical offsets added to spectra for clarity.

drawn about the geometric relationship of the $[(\text { bipy }) \mathrm{Pt}(\mathrm{en})]^{2+}$ molecular ions relative to the helical axis of DNA are rather uncertain because of a lack of knowledge concerning the directions and positions of the relevant transition-moment vectors. It might be justified, however, to estimate the relative orientation of the bound ligand molecules from this data. The bands at 1450 and $770 \mathrm{~cm}^{-1}$ can be tentatively assigned to in-plane $\mathrm{C}-\mathrm{C}(\mathrm{N})$ stretching and out-of-plane $\mathrm{C}-\mathrm{H}$ deformation vibrations of the aromatic bipyridyl rings of DNA-bound $[(\text { bipy }) \mathrm{Pt}(\mathrm{en})]^{2+}$ with transition moments essentially parallel and perpendicular to the pertinent ring planes, respectively. The spectra of the complex show perpendicular $(R>1)$ and parallel $(R<1)$ linear dichroism of the bands at 1450 and $770 \mathrm{~cm}^{-1}$, respectively. Thus, both these results indicate that the bipyridyl rings of the ligand are roughly perpendicular to the DNA helix axis. This is compatible with groove binding.

It should be noted that both the MAS-NMR and IR-LD techniques show no differences for the phosphate group orientation in either regular $B$-DNA or the NaDNA $\cdot[\text { (bipy)Pt(en) }]^{2+}$ complex. The important point is that attaching the $[(\text { bipy }) \mathrm{Pt}(\mathrm{en})]^{2+}$ ligand does not change the phosphate group orientations in any measurable way, as expected, since the overall geometry of the DNA molecule is not changed significantly by the $[(\text { bipy }) \mathrm{Pt}(\mathrm{en})]^{2+}$ ligand. (A similar result was also observed for the NaDNA - netropsin complex [14].) This is in contrast to the predictions of the ladder model. It is also noteworthy that the MAS-NMR and IR-LD measurements both yield $\beta_{P D} \approx 55^{\circ}-60^{\circ}$ (with an uncertainty of about $5^{\circ}$ ). In contrast, the ladder model predicts two peaks with $\beta_{P D}=27^{\circ}$ and $84^{\circ}$.

Additional information about the secondary structure of the DNA in this complex can be obtained from Fig. 15 because $A$ - and $B$-DNA have conformationally sensitive vibra- 
tional modes. The spectrum from the pure NaDNA film has IR modes of the $A$ conformation at about $861 \mathrm{~cm}^{-1}$ and of the $B$ conformation at about $834 \mathrm{~cm}^{-1}[36,57]$, showing that this sample contains a mixture of both conformations. In contrast, the IR spectrum from the film of the NaDNA $\cdot[(\text { bipy }) \operatorname{Pt}(\text { en })]^{2+}$ complex does not have the $A$-form marker band (at about $861 \mathrm{~cm}^{-1}$ ) and does have the $B$-form marker band (at about $834 \mathrm{~cm}^{-1}$ ). This is clear evidence that the DNA in the NaDNA. $[(\text { bipy }) \operatorname{Pt}(\text { en })]^{2+}$ complex is in the $B$ conformation at $75 \% \mathrm{RH}$. It is also noteworthy that the ladder model of the DNA. $[(\text { bipy }) \mathrm{Pt}(\mathrm{en})]^{2+}$ complex predicts that half of the sugar groups are in the $C 3^{\prime}$ endo pucker. Since the $861 \mathrm{~cm}^{-1}$ mode is believed to be associated with $C 3^{\prime}$ endo ribose sugar, the ladder model predicts that the $861 \mathrm{~cm}^{-1}$ mode will be observed from the DNA. $[(\text { bipy }) \mathrm{Pt}(\mathrm{en})]^{2+}$ complex. On the contrary, this mode is not observed in our experiments.

It should be noted that unpolarized IR absorption experiments on unoriented films of the DNA - daunomycin complex observed significant changes in the frequencies of some of the DNA modes due to the intercalation of daunomycin into the DNA [60]. An additional argument against the ladder model is that no such changes are observed in the present IR experiments on the DNA. [(bipy) $\mathrm{Pt}($ en $)]^{2+}$ complex.

\section{E. Mechanochemistry of fibers in ethanolic bath}

NaDNA fiber bundles were found to rapidly increase in length by $9 \%$ as they were brought into the ethanolic bath containing [(bipy) $\mathrm{Pt}(\mathrm{en})] \mathrm{I}_{2}$. This elongation was essentially completed within $30 \mathrm{~s}$. Thereafter, the length remained constant indicating that the complete formation of the DNA $[(\text { bipy }) \operatorname{Pt}(\text { en })]^{2+}$ complex had occurred very rapidly in this very thin sample [40] and with this high concentration and large excess of $[\text { (bipy) } \operatorname{Pt}(\mathrm{en})]^{2+}$. Returning such a sample back to the original ethanolic bath free of [(bipy) $\mathrm{Pt}(\mathrm{en})]^{2+}$ caused a contraction down to $L / L_{0}=1.02$ within $12 \mathrm{~h}$, indicating that a significant portion of the ligand had been released from the complex.

The helical axes of the DNA molecules are aligned in the direction of the fiber, but there is a much smaller order in the plane perpendicular to the helical axis than in the films formed during the drying procedure. Since all of our other experiments have been performed on such wet-spun films, which are known to be highly crystalline, it is important to verify that the $[(\text { bipy }) \mathrm{Pt}(\mathrm{en})]^{2+}$ molecular ion is bound to the DNA in these more or less amorphous fibers in the same manner as in the highly crystalline, wet-spun films. In order to verify this, $\mathrm{x}$-ray diffraction experiments were performed on two thick fiber bundles in ethanolic baths: one of pure NaDNA and the other of the NaDNA. $[(\text { bipy }) \operatorname{Pt}(\text { en })]^{2+}$ complex, shown in Figs. 16(a) and 16(b), respectively. The pure DNA fiber shows no crystalline order, as expected. The $\mathrm{x}$-ray pattern from the DNA. $[(\text { bipy }) \mathrm{Pt}(\mathrm{en})]^{2+}$ fiber also shows little order except for meridional reflections due to the ordering of the $[(\text { bipy }) \mathrm{Pt}(\mathrm{en})]^{2+}$ along the DNA molecule. The spacings of these reflections match the observations from the highly crystalline, wet-spun films. This verifies that the $[\text { (bipy) } \mathrm{Pt}(\mathrm{en})]^{2+}$ molecular ions have bound to the DNA in these amorphous fibers in the same manner that they are bound to the DNA in the highly crystalline, wet-spun films.

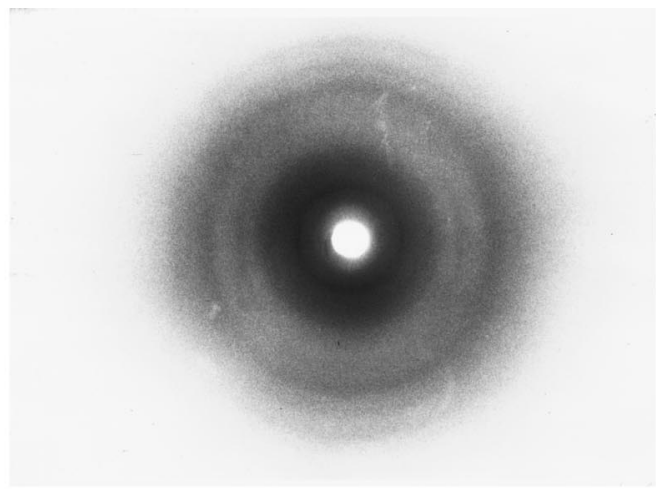

(a)

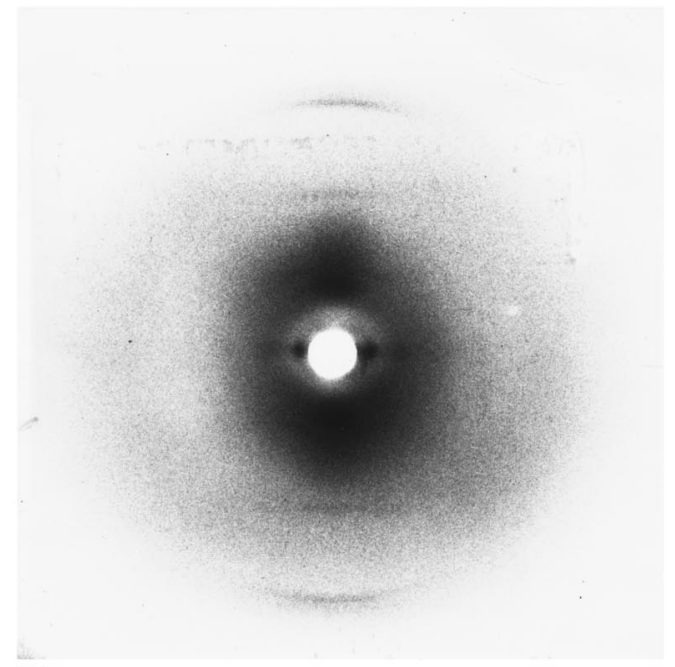

(b)

FIG. 16. X-ray diffraction patterns of wet-spun fibers of (a) pure NaDNA and (b) NaDNA. $\left[(\text { bipy)Pt(en) }]^{2+}\right.$ complex in thin-walled capillaries filled with a $65 \%$ ethanol bath without and with $2.81 \mathrm{~m} M[(\text { bipy }) \mathrm{Pt}(\mathrm{en})]^{2+}$, respectively. The baths also contained $30 \mathrm{~m} M \mathrm{NaCl}+2 \mathrm{~m} M \mathrm{Na}_{3}$-citrate.

It is of interest to compare with an analogous mechanochemical experiment performed with NaDNA fibers and the drug netropsin. This drug binds in the minor groove and is known to induce the $B$ form of DNA. As can be seen from Fig. 5 of Song et al. [51], the transfer of the DNA fiber bundle from $68 \%$ ethanol to $68 \%$ ethanol containing $0.8 \mathrm{~m} M$ netropsin and $0.05 \mathrm{mM} \mathrm{NaCl}$ caused about $1 \%$ elongation due to the $A-B$ transition of the DNA. However, in the present experiments on the DNA. $[(\text { bipy }) \operatorname{Pt}(\text { en })]^{2+}$ complex, $10 \mathrm{mg}$ platinum weights were used rather than the $30 \mathrm{mg}$ weights used in the experiments with netropsin. Consequently, the fibers in the present experiments should contain a larger fraction of A-DNA [61]. Furthermore, the concentration of $[(\text { bipy }) \mathrm{Pt}(\mathrm{en})]^{2+}$ was much higher $(3.37 \mathrm{mM}$ compared to $0.8 \mathrm{~m} M$ for netropsin), which should yield a more effective $A-B$ transition in our fibers. So, it may be concluded that part of the $9 \%$ elongation observed in our mechanochemistry experiments is due to the $A-B$ transition of the fraction of $A$-DNA occurring in the DNA fibers.

The assumption that the $9 \%$ fiber elongation is partly due to the $A-B$ transition is also supported by the $\mathrm{x}$-ray patterns of DNA $[(\text { bipy }) \mathrm{Pt}(\mathrm{en})]^{2+}$ fibers in ethanol containing $[(\text { bipy }) \operatorname{Pt}(\mathrm{en})]^{2+}$. The meridional doublet reflections at 
$1.86 \AA^{-1}$ in Fig. 5 are also discernible here. This indicates that the DNA $\cdot[\text { (bipy) } \mathrm{Pt}(\text { en })]^{2+}$ fibers formed in the mechanochemistry experiment also contain the DNA in the "distorted' $B$ conformation.

The ladder model predicts a $50 \%$ expansion upon attachment by the $[(\text { bipy }) \operatorname{Pt}(\text { en })]^{2+}$ molecular ion if all of the DNA is initially in the $B$ conformation. Since our NaDNA fibers in $68 \%$ ethanol have an admixture of $A$-DNA, as concluded above, the observed expansion would be even greater than $50 \%$ since the elongation caused by the $A-B$ transition would also be observed. Clearly, the mechanochemistry experiment is in contradiction with the predictions of the ladder model.

\section{SUMMARY}

Our experimental evidence supports a "distorted" $B$ conformation for the DNA in the $\mathrm{NaDNA} \cdot[\text { (bipy) } \mathrm{Pt}(\text { en })]^{2+}$ complex with one $[\text { (bipy) } \mathrm{Pt}(\mathrm{en})]^{2+}$ molecular ion for every three DNA base pairs. This amount of $[\text { (bipy) } \mathrm{Pt}(\text { en })]^{2+}$ in the basic complex is shown by (1) the x-ray diffraction pattern for the 0.33 molar ratio sample and (2) the $0.61,1.22$, and $1.82 \AA^{-1}$ peaks (showing a repeat distance of $10.3 \AA$ ) in the neutron diffraction data. The rise per residue in the complex is $3.31 \AA$. The neutron data are consistent with a centered orthorhombic unit cell with $a=22.65 \AA$ and $b$ $=32.2 \AA$ for the NaDNA. $[(\text { bipy }) \operatorname{Pt}(\text { en })]^{2+}$ complex in the crystalline state. The value of $c$ has not been determined by our data, but is believed to be in the range from 30.9 to $33.1 \AA$. Additional evidence for a $B$ conformation of the $\mathrm{NaDNA} \cdot[\text { (bipy)Pt(en) }]^{2+}$ complex is found in both the MAS-NMR and IR-LD data. Both techniques show that the phosphate group orientation is indistinguishable from that found in $B$-DNA. Finally, the unpolarized IR absorption experiments reveal the presence of the $B$-form "marker bands" for the NaDNA. $[\text { (bipy) } \mathrm{Pt}(\text { en })]^{2+}$ complex.
This work has produced several pieces of evidence in contradiction to the predictions of the ladder model of the DNA $\cdot[\text { (bipy)Pt(en) }]^{2+}$ complex. (1) The x-ray diffraction pattern from a DNA $\cdot[\text { (bipy) } \mathrm{Pt}(\text { en })]^{2+}$ sample with a molar ratio of 0.33 (that is, one $[\text { (bipy) } \mathrm{Pt}(\mathrm{en})]^{2+}$ molecular ion for every three DNA base pairs) shows that the complex is fully formed. This is in contrast to the predicted 0.50 molar ratio of the ladder model. (2) The neutron diffraction pattern in the direction perpendicular to the helical axis predicted by the ladder model is in poor agreement with the experimental observations. (3) The ladder model predicts that the MASNMR experiments should detect two peaks of equal strength for phosphate group orientations in contrast to our experimental observations. (4) The ladder model predicts that the phosphate group orientations should be very different from those of $B$-DNA. In contrast, both the MAS-NMR and IR-LD experiments find that the observed phosphate group orientations are indistinguishable from those observed in B-DNA. (5) The ladder model predicts that a DNA fiber should expand in length by at least $50 \%$ upon attachment by $[(\text { bipy }) \operatorname{Pt}(\text { en })]^{2+}$. In contrast, only a $9 \%$ expansion is observed, and part (or all) of this expansion is caused by the $A-B$ transition of the fraction of $A$-DNA in the fibers.

Finally, it should be stated that our results are valid only for complexes formed in condensed samples; it is possible that the $[\text { (bipy) } \operatorname{Pt}(\text { en })]^{2+}$ molecular ions bind to DNA in a different manner (possibly including intercalation) under different conditions (such as in solution).

\section{ACKNOWLEDGMENTS}

The authors thank Professor H. Fritzsche for helpful comments and D. Truebner and H. Lippert for technical assistance. The work was supported by the Swedish Medical Research Council.
[1] W. Saenger, Principles of Nucleic Acid Structure (SpringerVerlag, New York, 1984).

[2] N.R. Kallenbach, Chemistry and Physics of DNA-Ligand Interactions (Oxford University Press, Oxford, 1990).

[3] S. Neidle, DNA Structure and Recognition (Oxford University Press, Oxford, 1994).

[4] J.B. Chaires, Biopolymers 44, 201 (1997).

[5] S.J. Lippard, P.J. Bond, K.C. Wu, and W.R. Bauer, Science 194, 726 (1976).

[6] M. Howe-Grant, K.C. Wu, W.R. Bauer, and S.J. Lippard, Biochemistry 15, 4339 (1976).

[7] M. Howe-Grant and S.J. Lippard, Biochemistry 18, 5762 (1979).

[8] S. Arnott, P.J. Bond, and R. Chandrasekaran, Nature (London) 287, 561 (1980).

[9] S. Arnott and R. Chandrasekaran, in Proceedings of the Second SUNYA Conversation in the Discipline Biomolecular Stereodynamics, Vol. I, edited by R.H. Sarma (Adenine Press, New York, 1981), p. 99.

[10] R.E. Franklin and R.G. Gosling, Acta Crystallogr. 6, 673 (1953).
[11] R.E. Franklin and R.G. Gosling, Acta Crystallogr. 6, 678 (1953).

[12] R.E. Franklin and R.G. Gosling, Nature (London) 171, 9 (1953).

[13] M.H.F. Wilkins, A.R. Stokes, and H.R. Wilson, Nature (London) 171, 4 (1953).

[14] Z. Song, O.G. Antzutkin, Y.K. Lee, S.C. Shekar, A. Rupprecht, and M.H. Levitt, Biophys. J. 73, 1539 (1997).

[15] A. Pichler, S. Rudisser, M. Mitterbock, C.G. Huber, R.H. Winger, K.R. Liedl, A. Hallbrucker, and E. Mayer, Biophys. J. 77, 398 (1999).

[16] L. van Dam and M.H. Levitt (unpublished)

[17] A. Szabó, R.A. Flowers, B.J. Carter, and S.A. Lee, Phys. Rev. E 58, 7754 (1998).

[18] K. Schmidt-Rohr and H.W. Spiess, Multidimensional SolidState NMR and Polymers (Academic Press, London, 1994).

[19] H.W. Spiess, Chem. Rev. 91, 1321 (1991).

[20] H. Shindo, Adv. Biophys. 20, 39 (1985).

[21] P. Tang, R.A. Santos, and G.S. Harbison, Adv. Magn. Reson. 13, 225 (1989).

[22] T.M. Alam and G.P. Drobny, Chem. Rev. 91, 1545 (1991). 
[23] J. Herzfeld, R.G. Griffin, and R.A. Haberkorn, Biochemistry 17, 2711 (1978).

[24] G.S. Harbison and H.W. Spiess, Chem. Phys. Lett. 124, 128 (1986).

[25] M.M. Maricq and J.S. Waugh, J. Chem. Phys. 70, 3300 (1979).

[26] D.A. Varshalovich, A.N. Moskalev, and V.K. Khersonskii, Quantum Theory of Angular Momentum (World Scientific Publishing, Singapore, 1988).

[27] J. Pilet and J. Brahms, Biophys. J. 12, 387 (1973).

[28] B. Norden, M. Kubista, and T. Kurucsev, Q. Rev. Biophys. 25, 51 (1992).

[29] W. Pohle, V.B. Zhurkin, and H. Fritzsche, Biopolymers 23, 2603 (1984).

[30] R.C.B. Fraser, J. Chem. Phys. 21, 1511 (1953).

[31] H. Fritzsche, H. Lang, and W. Pohle, Biochim. Biophys. Acta 432, 409 (1976).

[32] J. Brahms, J. Pilet, T.-T. Phuong Lan, and L.R. Hill, Proc. Natl. Acad. Sci. U.S.A. 70, 3352 (1973).

[33] J. Pilet and M. Leng, Proc. Natl. Acad. Sci. U.S.A. 79, 26 (1982).

[34] W. Pohle, Stud. Biophys. 137, 141 (1990).

[35] W. Pohle and H. Fritzsche, Nucleic Acids Res. 3, 3331 (1976).

[36] E. Taillandier and J. Liquier, Methods Enzymol. 211, 307 (1992).

[37] G.J. Thomas, Jr. and M. Tsuboi, Advances in Biophysical Chemistry (JAI Press, Greenwich, CT, 1993), Vol. 3, p. 1.

[38] A. Rupprecht, Acta Chem. Scand. 20, 494 (1966).

[39] A. Rupprecht, Biotechnol. Bioeng. 12, 93 (1970).

[40] A. Rupprecht, J. Piskur, J. Schultz, L. Nordenskiold, Z. Song, and G. Lahajnar, Biopolymers 34, 897 (1994).

[41] J. Piskur and A. Rupprecht, FEBS Lett. 375, 174 (1995).

[42] G.W. Watt and D.G. Upchurch, Inorg. Nucl. Chem. Lett. 2, 363 (1966).

[43] A. Rupprecht and H. Fritzsche, Spectrosc. Int. J. 4, 1 (1985).
[44] A. Rupprecht and B. Forslind, Biochim. Biophys. Acta 204, 304 (1970)

[45] A. Rupprecht, L. Nordenskiold, L. Einarsson, J. Schultz, C.S. Huldt, and G. Lahajnar, Acta Chem. Scand. 45, 216 (1991).

[46] H.W. Wyckoff, Ph.D. dissertation, Massachusetts Institute of Technology, 1955 (unpublished).

[47] S.M. Lindsay, S.A. Lee, J.W. Powell, T. Weidlich, C. Demarco, G.D. Lewen, N.J. Tao, and A. Rupprecht, Biopolymers 27, 1015 (1988).

[48] M.H. Levitt, J. Magn. Reson. 126, 164 (1997).

[49] G.S. Harbison, V.-D. Vogt, and H.W. Spiess, J. Chem. Phys. 86, 1206 (1987).

[50] W. Pohle, M. Bohl, J. Flemming, and H. Bohlig, Biophys. Chem. 35, 213 (1990).

[51] Z. Song, A. Rupprecht, and H. Fritzsche, Biophys. J. 68, 1050 (1995).

[52] A. Rupprecht, Biopolymers 9, 825 (1970).

[53] R. Brandes, R.R. Vold, D.R. Kearns, and A. Rupprecht, Biopolymers 27, 1159 (1988).

[54] H. Grimm and A. Rupprecht, Physica B 174, 291 (1991).

[55] K. Grzeskowiak, K. Yanagi, G.G. Prive, and R.E. Dickerson, J. Biol. Chem. 266, 8861 (1991).

[56] P. Tang, C.-L. Juang, and G.S. Harbison, Science 249, 70 (1990).

[57] W. Pohle and H. Fritzsche, Stud. Biophys. 104, 303 (1984).

[58] W. Pohle, and J. Flemming, J. Biomol. Struct. Dyn. 4, 243 (1986).

[59] H. Fritzsche, Nucleic Acids Res. 22, 787 (1994).

[60] Y.Z. Chen, A. Szabó, D.F. Schroeter, J.W. Powell, S.A. Lee, and E.W. Prohofsky, Phys. Rev. E 55, 7414 (1997).

[61] G. Albiser, M. Harmouchi, and S. Premilat, J. Biomol. Struct. Dyn. 6, 359 (1988).

[62] E. Taillandier, J. Liquier, and J.A. Taboury, Advances in Infrared and Raman Spectroscopy, edited by R.J.H. Clark and R.E. Hester (Wiley, New York, 1985), Vol. 12, p. 65. 